\title{
Biliary stenting: Indications, choice of stents and results: European Society of Gastrointestinal Endoscopy (ESGE) clinical guideline
}

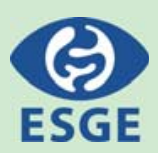

Authors

Institutions
J.-M. Dumonceau' ${ }^{1}$ A. Tringali², D. Blero ${ }^{3}$, J. Devière ${ }^{3}$, R. Laugiers ${ }^{4}$, D. Heresbach ${ }^{5}$, G. Costamagna ${ }^{2}$

Institutions are listed at the end of article. submitted 5. May 2011 accepted after revision 26. October 2011

\section{Bibliography}

Dol http://dx.doi.org/ 10.1055/s-0031-1291633

Published online: 1.2.2012

Endoscopy 2012; 44: 277-298

(c) Georg Thieme Verlag KG

Stuttgart · New York

ISSN 0013-726X

\section{Corresponding author}

J.-M. Dumonceau, MD PhD

Division of Gastroenterology and Hepatology

Geneva University Hospitals

Rue Micheli-du-Crest 24

1205 Geneva

Switzerland

Fax: $+41+22+3729366$

jmdumonceau@hotmail.com
This article is part of a combined publication that expresses the current view of the European Society of Gastrointestinal Endoscopy about endoscopic biliary stenting. The present Clinical Guideline describes short-term and long-term results of biliary stenting depending on indications and stent models; it makes recommendations on when, how, and with which stent to perform biliary drainage in most common clinical settings, including in patients with a potentially resectable malignant biliary obstruction and in those who require palliative drainage of common bile duct or hilar strictures. Treatment of benign conditions (strictures related to chronic pancreatitis, liver transplantation, or cholecystectomy, and leaks and failed biliary stone extraction) and manage-

\section{Introduction}

$\nabla$

This article is part of a combined publication that expresses the current view of the European Society of Gastrointestinal Endoscopy (ESGE) about endoscopic biliary stenting for benign and malignant conditions; the other part of the publication describes the models of biliary stents available and the techniques used for stenting [1].

\section{Methods \\ $\nabla$}

The ESGE commissioned and funded these guidelines. The methodology was similar to that used for other ESGE guidelines [2,3]. Briefly, subgroups were charged with a series of key questions (see Appendix e1, available online). Search terms included, at a minimum, "biliary" and "stent" as well as words pertinent to specific key questions. Searches were performed on Medline (via Pubmed), the Cochrane Library, Embase, and the internet. The number of articles retrieved and selected for each task force is indicated in the Evidence Table (see Appendix e2, available online). ment of complications (including stent revision) are also discussed. A two-page executive summary of evidence statements and recommendations is provided. A separate Technology Review describes the models of biliary stents available and the stenting techniques, including advanced techniques such as insertion of multiple plastic stents, drainage of hilar strictures, retrieval of migrated stents and combined stenting in malignant biliary and duodenal obstructions.

The target readership for the Clinical Guideline mostly includes digestive endoscopists, gastroenterologists, oncologists, radiologists, internists, and surgeons while the Technology Review should be most useful to endoscopists who perform biliary drainage.

Evidence levels and recommendation grades used in these guidelines were slightly modified from those recommended by the Scottish Intercollegiate Guidelines Network ( $\bullet$ Table 1 ) [4]. Subgroups agreed electronically on draft proposals that were presented to the entire group for general discussion during two meetings held in 2010 and 2011. The subsequent Guideline version was again discussed using electronic mail until unanimous agreement was reached. Searches were rerun in December 2010 (this date should be taken into account for future updates). The final draft was approved by all members of the guideline development group; it was sent to all individual ESGE members in April 2011 and, after incorporation of their comments, it was endorsed by the ESGE Governing Board prior to submission to Endoscopy for international peer review. It was also approved by the British Society of Gastroenterology and the Deutsche Gesellschaft für Verdauungs- und Stoffwechselkrankheiten. The final revised version was approved by all members of the Guideline development group before publication. 


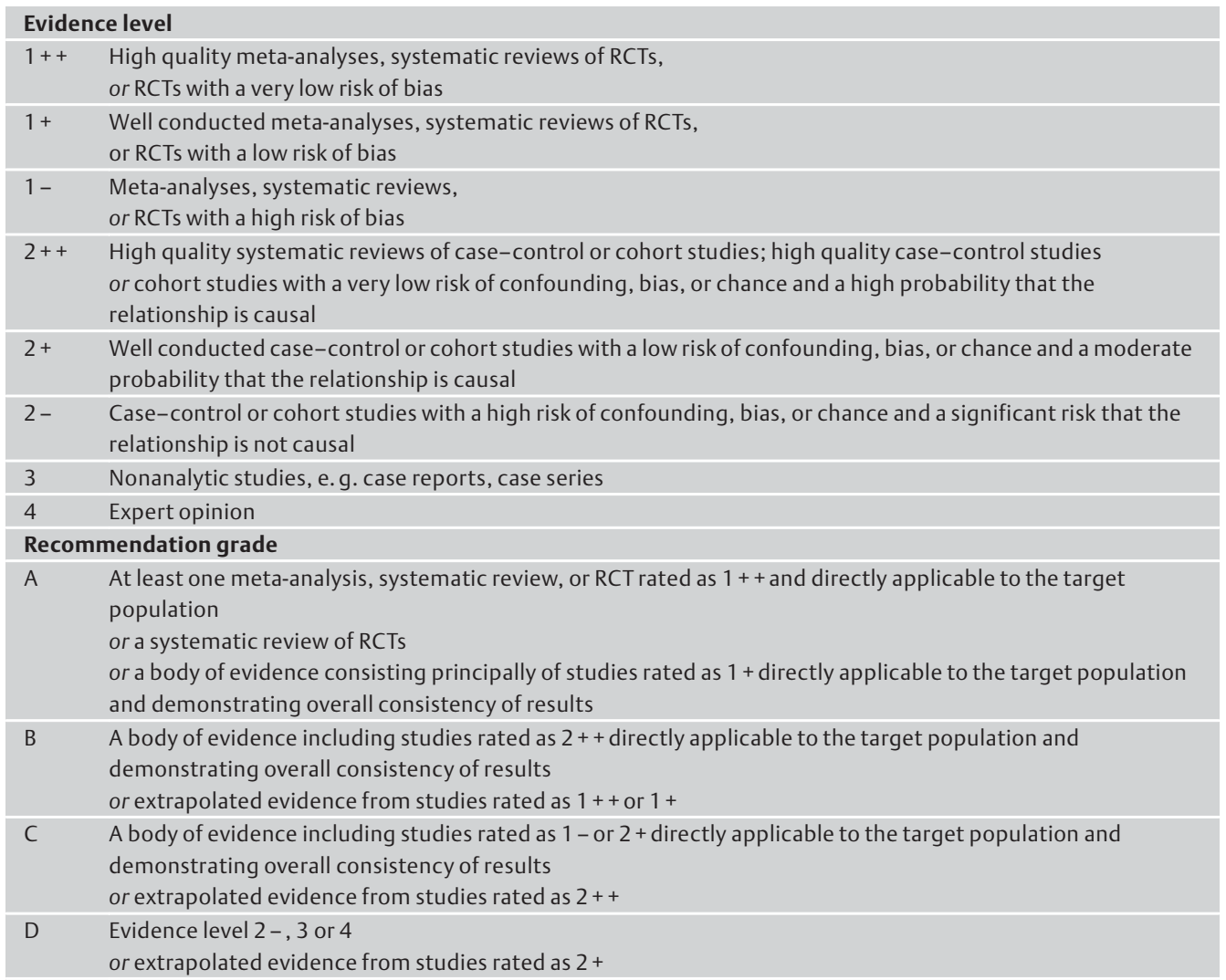

Table 1 Definitions of categories for evidence levels and recommendation grades used in these guidelines [4].

$\mathrm{RCT}$, randomized controlled trial.

Evidence statements and recommendations are stated in italics, key evidence statements and recommendations are in bold. This Guideline will be considered for review in 2015, or sooner if important new evidence becomes available. Any updates to the Guideline in the interim period will be noted on the ESGE website: http://www.esge.com/esge-guidelines.html.

\section{Summary of statements and recommendations $\nabla$}

\subsection{Stent insertion}

Biliary sphincterotomy is not necessary for inserting a single plastic stent or a self-expandable metal stent(SEMS) (Evidence level 1+) but it may facilitate more complex stenting procedures (Evidence level 4). Results of randomized controlled trials (RCTs) comparing biliary stenting with or without biliary sphincterotomy are contradictory. The anticipated benefits of pre-stenting biliary sphincterotomy should be weighed against its risks on a case-by-case basis (Recommendation grade $B$ ). If biliary sphincterotomy is performed, blended electrosurgical current should be used (Recommendation grade $A$ ).

Endoscopic biliary stenting is technically successful in $>90 \%$ of attempted cases. In the case of initial failure, multiple treatment options, including repeat endoscopic attempt, have provided technical success in $>80 \%$ of cases (Evidence level $1++$ ). In the case of initial failure at endoscopic biliary stenting, the indication for stenting should be re-evaluated and, if it is maintained, the best treatment option should be selected depending on the cause of failure, the anatomy, the degree of emergency, and available resources (Recommendation grade $A$ ).

\subsection{Short-term (1-month) efficacy of stents}

for biliary drainage

Plastic stents and SEMSs provide similar short-term results with respect to clinical success, morbidity, mortality, and improvement in quality of life. Among plastic biliary stents, polyethylene models allow relief of obstruction more frequently than Teflon-made stents of the Tannenbaum or Amsterdam type; among currently available SEMS models no significant differences were reported at 30 days (Evidence level $1++$ ). Patient-related factors associated with failure to resolve jaundice after biliary stenting include a high baseline bilirubin level, diffuse liver metastases, and International Normalized Ratio (INR) $\geq 1.5$ (Evidence level $2+$ ).

Short-term considerations should not affect the choice between biliary plastic stents and SEMSs; among plastic stents, Teflonmade models should be avoided if identical designs of polyethylene-made stents are available (Recommendation grade A). In the case of cholangitis or decrease in total bilirubin level of $<\mathbf{2 0} \%$ from baseline at $\mathbf{7}$ days post stent insertion, biliary imaging or endoscopic revision should be considered (Recommendation grade $\mathrm{D}$ ).

\subsection{Long-term stent efficacy for palliation of malignant} common bile duct (CBD) obstruction

For palliation of malignant CBD obstruction, endoscopic biliary drainage is effective in $>80 \%$ of cases (Evidence level $1++$ ), with lower morbidity than surgery (Evidence level $1+$ ). SEMSs present a lower risk of recurring biliary obstruction than single plastic stents, without difference in patient survival, at least if patients are regularly followed (Evidence level 1+). Initial insertion of a plastic stent is most cost-effective if patient life expectancy is shorter than 4 months; if it is longer than 4 months then initial insertion of a SEMS is more cost-effective (Evidence level 2+). Amongst SEMS 
models measuring $10 \mathrm{~mm}$ in diameter, no difference has been clearly demonstrated, including between covered and uncovered models. Amongst plastic stents, those measuring $10 \mathrm{Fr}$ in diameter, and possibly some stent designs (i.e., DoubleLayer and stents equipped with an antireflux valve), provide the longest biliary patency; drug administration does not prolong stent patency (Evidence level $1+$ ).

Palliative drainage of malignant CBD obstruction should be first attempted endoscopically (Recommendation grade A). Initial insertion of a 10-Fr plastic stent is recommended if the diagnosis of malignancy is not established or if expected survival is < 4 months (Recommendation grade $\mathrm{C}$ ). No drug prescription is recommended to prolong stent patency (Recommendation grade A). In patients with an established diagnosis of malignancy, initial insertion of a 10-mm diameter SEMS is recommended if expected survival is $>4$ months (or if SEMS cost is $<50 \%$ that of endoscopic retrograde cholangiopancreatography [ERCP]). Amongst biliary SEMSs, a model that is economical and with which the endoscopist has personal experience is recommended (Recommendation grade C).

\subsection{Indications for stenting and stent selection in} patients with a potentially resectable CBD obstruction In patients with a resectable malignant CBD stricture, insertion of a plastic biliary stent followed by delayed surgery is associated with a higher morbidity compared with surgery at 1 week (Evidence level $1++$ ). Some models of biliary SEMSs (short intrapancreatic or covered) do not impede pancreatic resection and may be used for preoperative biliary drainage in patients with malignant $C B D$ obstruction whose surgical status is uncertain (Evidence level 2+).

We recommend preoperative drainage of potentially resectable malignant CBD obstruction only in patients who are candidates for neoadjuvant therapies, in patients with acute cholangitis, or in patients with intense pruritus and delayed surgery (Recommendation grade A). Plastic as well as short intrapancreatic or covered SEMSs may be used, with a preference for SEMSs in patients who are candidates for neoadjuvant therapies (Recommendation grade $\mathrm{C}$ ).

\subsection{Complications of biliary stenting}

\subsubsection{Early complications}

Early complications develop in approximately $5 \%$ of patients after attempted endoscopic biliary stenting and are not related to the type of stent used (Evidence level $1++$ ). The reader is referred to other guidelines for detailed recommendations about the prevention of infection, pancreatitis, and bleeding.

\subsubsection{Late complications}

Late complications of biliary stenting mostly consist of stent dysfunction, which is approximately twice as frequent with plastic stents compared with SEMSs, and, much less frequently, cholecystitis, duodenal perforation, and bleeding ulcer (Evidence level 1+). Approximately $5 \%$ of plastic stents and partially covered SEMSs migrate while $1 \%$ of uncovered SEMSs and $20 \%$ of fully covered SEMSs migrate. After distal migration, most plastic stents are spontaneously eliminated. (Evidence level $1+$ ). Migration of plastic stents is more frequent in benign as compared with malignant biliary strictures, and with single as compared with multiple stents. Endoscopic treatment of stent migration is feasible in $>90 \%$ of cases with low morbidity (Evidence level 2+).
In patients with migrated stents, we recommend ERCP for removing stents that have not been spontaneously eliminated and for stenting potentially persistent strictures. In the case of persistent biliary stricture, we recommend inserting multiple plastic stents or, if a SEMS is indicated, an uncovered model (Recommendation grade $\mathrm{C}$ ).

Stent occlusion is caused by sludge (in plastic stents), or by tissue ingrowth/overgrowth or sludge (in SEMSs) (Evidence level 1-). Endoscopic restoration of biliary patency is successful in $>95 \%$ of patients with stent obstruction and exceptionally gives rise to complications (Evidence level 2+). For occluded SEMSs, mechanical SEMS cleansing is poorly effective for restoring biliary patency; inserting a second SEMS within the occluded SEMS yields a longer biliary patency than inserting a plastic stent, particularly if one of the two SEMSs (initially placed or placed for treating stent dysfunction) is a covered model (Evidence level 2-).

We recommend ERCP in patients with biliary stent occlusion, except when this is considered futile in patients with advanced malignant disease. Plastic stents should be exchanged for plastic (single or multiple) stents or a SEMS, according to the criteria stated above. Occlusion of biliary SEMSs should be treated by inserting a second SEMS within the occlusion (a covered model should be selected if the first SEMS was uncovered) or, in the case of a life expectancy $\leq 3$ months, by inserting a plastic stent (Recommendation grade $\mathrm{C}$ ).

Neoplastic involvement of the cystic duct and gallbladder stones are the key risk factors for SEMS-related cholecystitis (Evidence level $2+$ ).

\subsection{Particular cases}

\subsubsection{Hilar strictures}

In the case of malignant hilar stricture (MHS), assessment of tumor resectability by CT or MRI may be affected by the presence of biliary stents (Evidence level 2+). Resectability of MHS should be evaluated by imaging techniques in the absence of biliary stents (Recommendation grade $\mathrm{C}$ ).

In MHS of Bismuth-Corlette type $\geq 2$, better biliary drainage might be achieved with fewer infective complications by the percutaneous as compared with the endoscopic route (Evidence level 1-). Drainage by means of a combined endoscopic and percutaneous approach may be necessary to treat infective complications of MHS, especially in the setting of opacified and undrained intrahepatic biliary ducts. Endoscopic drainage of complex MHS more frequently fails in low volume vs. high volume centers (Evidence level $2-$ ). Local expertise for percutaneous and endoscopic biliary drainage may not be available in many centers (Evidence level 1-).

The choice between endoscopic or percutaneous drainage for MHS should be based on local expertise (Recommendation grade D); endoscopic drainage should be performed in high volume centers with experienced endoscopists and multidisciplinary teams (Recommendation grade $\mathrm{C}$ ).

MRI seems to be slightly more accurate than CT for assessing the level of obstruction in MHS; both methods allow measurement of the volume of liver lobes. This ductal and parenchymal information is useful for directing palliative drainage of MHS (Evidence level $2+$ ). We recommend performance of MRI to assess the hepatobiliary anatomy before attempting drainage of MHS (Recommendation grade $C$ ).

After bilateral biliary opacification upstream from MHS, morbidity and mortality rates are higher with unilateral compared with bilateral biliary drainage (Evidence level 2-). A low incidence of cholangitis has consistently been achieved when specific endoscopic 
techniques were used to target drainage to duct(s) selected on the basis of MRI or CT (Evidence level 2+). Draining $>50 \%$ of the liver volume is associated with higher drainage effectiveness and longer survival than draining $<50 \%$ of the liver volume (Evidence level 2-).

In MHS, the liver sector(s) to be drained should be selected before beginning ERCP, based on MRI or CT, with the aim of draining $>50 \%$ of the liver volume. Bile $\operatorname{duct}(\mathrm{s})$ unintentionally opacified upstream from an MHS should be drained during the same procedure. Antibiotics should be administered in case of anticipated incomplete biliary drainage and, if drainage proves to be incomplete, they should be continued until complete drainage is achieved (Recommendation grade $C$ ).

Plastic stents and uncovered SEMSs yield similar short-term results in patients with MHS but SEMSs provide a longer biliary patency compared with plastic stents (only uncovered SEMSs are used in this setting to prevent occlusion of side branches) (Evidence level 1 -). Plastic stenting is recommended as long as no definitive decision about curative/palliative treatment has been taken. If a decision for palliative treatment is taken, insertion of SEMSs is recommended in patients with life expectancy $>3$ months or with biliary infection (Recommendation grade B).

SEMSs do not impede light delivery for photodynamic therapy but adjustments of the light dose are required (Evidence level $2++$ ). Trans-SEMS photodynamic therapy for palliation of malignant hilar strictures should be administered in centers with well-trained personnel (Recommendation grade $D$ ).

Stent dysfunction in patients with MHS is treated as follows: plastic stents are removed, ducts are cleaned, and new stents are inserted; uncovered SEMSs are cleaned and, in the case of persistent stricture, new stents are inserted. The choice between plastic stents or SEMSs for re-stenting is based on the degree of biliary infection and the life expectancy (Recommendation grade D).

\subsubsection{Benign strictures}

In the case of benign CBD strictures, temporary simultaneous placement of multiple plastic stents is technically feasible in $>90 \%$ of patients; it is the endoscopic technique that provides the highest long-term biliary patency rate (90\% for postoperative biliary strictures and 65\% for those complicating chronic pancreatitis); it requires a mean of approximately four ERCPs over a 12-month period. Possible stricture recurrences after this treatment are usually successfully re-treated by ERCP. Temporary placement of single plastic stents provides poorer patency rates; treatment with uncovered SEMSs is plagued by high long-term morbidity; temporary placement of covered SEMSs is an investigational option that needs to be carefully evaluated by long-term follow-up studies (Evidence level $1+$ ).

In patients with benign CBD strictures, we recommend temporary placement of multiple plastic stents provided that the patient consents and is thought likely to be compliant with repeat interventions. The insertion of uncovered biliary SEMSs is strongly discouraged (Recommendation grade A). Covered SEMSs are a promising alternative for selected benign CBD strictures. Because of the risk of fatal septic complications, a recall system should be set up for the care of patients who do not present for ERCP at scheduled dates (Recommendation grade D).

\subsubsection{Bile leaks}

In the absence of transection of the $C B D$, endoscopic treatment (biliary sphincterotomy or temporary drainage associated with removal of any potentially associated biliary obstacle) allows healing of more than $90 \%$ of biliary leaks. Biliary stenting provides faster leak resolution than sphincterotomy alone; it is equally effective whether sphincterotomy is performed or not. Biliary sphincterotomy is associated with a risk of short-term and long-term complications, particularly in young patients (Evidence level 1+). In the case of temporary biliary stenting, biliary abnormalities (mostly sludge, stones, or persistent leak) can be found at the time of stent removal in a significant proportion of patients (Evidence level 2-). We recommend discussing the advantages and inconveniences of available treatment options with the patient before ERCP (e.g., the need for repeat ERCP in the case of stenting). At ERCP, one should pay particular attention to locating the leak and to detection of potentially associated biliary lesions or obstacles (e.g., retained stone) that require specific treatment. In the absence of such lesions, we recommend insertion of a plastic biliary stent without performance of sphincterotomy, and removal of the stent 4 to 8 weeks later. Endoscopic sphincterotomy alone is an alternative option, in particular in elderly patients (Recommendation grade B). At the time of stent removal, cholangiography and duct cleansing should be performed (Recommendation grade $D$ ).

\subsubsection{Temporary stenting for biliary stones}

In patients with irretrievable biliary stones, insertion of a plastic stent is effective in the short term to drain the bile ducts; it is frequently associated with partial (or even complete) stone dissolution that facilitates delayed endoscopic stone removal in most cases (Evidence level 1-). Addition of oral ursodeoxycholic acid does not increase the stone dissolution rate (Evidence level 1-) but a combination of oral ursodeoxycholic acid and terpene could be more effective (Evidence level 2-). Morbidity/mortality is high in the case of long-term biliary stenting (Evidence level 1+).

If ERCP fails to remove difficult biliary stones or is contraindicated, temporary (e.g., 3-month) plastic stenting should be considered. After biliary stent placement, the patient and referring physicians should be warned that, when used as a long-term measure, stent placement is associated with a high risk of cholangitis (Recommendation grade B). Addition of oral ursodeoxycholic acid associated with terpene should be considered (Recommendation grade D).

\section{Stent insertion}

$\nabla$

Biliary sphincterotomy is not necessary for inserting a single plastic stent or a SEMS (Evidence level 1+) but it may facilitate more complex stenting procedures (Evidence level 4). Results of randomized controlled trials (RCTS) comparing biliary stenting with or without biliary sphincterotomy are contradictory. The anticipated benefits of pre-stenting biliary sphincterotomy should be weighed against its risks on a case-by-case basis (Recommendation grade $B$ ). If biliary sphincterotomy is performed, blended electrosurgical current should be used (Recommendation grade A).

Biliary sphincterotomy is not necessary for inserting single plastic or metal biliary stents [5-9]. Three RCTs compared stent placement preceded or not by biliary sphincterotomy. The two RCTs that used plastic stents included a total of 244 patients with a malignant CBD stricture or a post-cholecystectomy bile leak; no significant difference in terms of early or late complications, including stent migration, was found between patients who had biliary sphincterotomy or not $[6,8]$. The third RCT included 72 patients treated with covered SEMSs and found a higher complication rate in patients who had undergone sphincterotomy compared with those who had not (49\% vs. $11 \%$, 
respectively; $\mathrm{P}=0.006$ ) [5]. Sphincterotomy-related complications were reported in $24 \%$ of patients (bleeding, $13 \%$; perforation, $11 \%)$, an incidence that is much higher compared with that reported with SEMS insertion in a meta-analysis (5.7\%) [10]; this discrepancy was not discussed in the article.

Pre-stenting biliary sphincterotomy is performed routinely by some endoscopists either because they think that this will facilitate stent exchange during follow-up or because more than one biliary stent is to be placed (e.g., in hilar obstruction or benign CBD stricture). If biliary sphincterotomy is performed, blended electrosurgical current should be used to decrease the risk of bleeding [11].

Endoscopic biliary stenting is technically successful in $>90 \%$ of attempted cases. In the case of initial failure, multiple treatment options, including repeat endoscopic attempt, have provided technical success in $>80 \%$ of cases (Evidence level $1++$ ). In the case of initial failure at endoscopic biliary stenting, the indication for stenting should be re-evaluated and, if it is maintained, the best treatment option should be selected depending on the cause of failure, the anatomy, the degree of emergency, and available resources (Recommendation grade $A$ ).

Biliary stenting may fail because of difficulties in reaching the papilla (e.g., duodenal stricture, previous surgery), in cannulating the bile duct, or in passing strictures in a retrograde fashion [10]. Factors contributing to failures include endoscopist experience [12,13], the volume of procedures per center [14], and inadequate patient sedation $[15,16]$. The type of stent used does not influence the success of stent insertion [10].

In a retrospective study of 47 initially failed ERCPs, the indication for ERCP was maintained in only $51 \%$ of cases (current proportions may be higher with the expansion of imaging techniques) [17]. In the case of failed endoscopic stenting, nonsurgical options that have provided technical success rates of $>80 \%$ include repeat attempt at ERCP by the same endoscopist (or another one in the same institution) $[17,18]$, percutaneous drainage (possibly followed by a rendezvous procedure) and EUS-guided cholangiography [19]. The latter technique should be reserved to endoscopists at tertiary care centers with advanced training in both EUS and ERCP.

\section{Short-term (1-month) efficacy of stents for biliary drainage}

Plastic stents and SEMSs provide similar short-term results with respect to clinical success, morbidity, mortality, and improvement in quality of life. Among plastic biliary stents, polyethylene models allow relief of obstruction relief more frequently than Teflon-made stents of the Tannenbaum or Amsterdam type; among currently available SEMS models no significant differences were reported at 30 days (Evidence level $1++$ ). Patient-related factors associated with failure to resolve jaundice after biliary stenting include a high baseline bilirubin level, diffuse liver metastases, and International Normalized Ratio (INR) $\geq 1.5$ (Evidence level $2+$ ).

Short-term considerations should not affect the choice between biliary plastic stents and SEMSs; among plastic stents, Teflonmade models should be avoided if identical designs of polyethylene-made stents are available (Recommendation grade A). In the case of cholangitis or decrease in total bilirubin level of $<20 \%$ from baseline at 7 days post stent insertion, biliary imaging or endoscopic revision should be considered (Recommendation grade D).
RCTs that compared various stent models for treating biliary obstruction have mostly included patients with a malignant distal biliary obstruction. A meta-analysis of these RCTs found that:

1. Plastic stents and SEMSs provide similar short-term success, defined by decrease in levels of jaundice, serum bilirubin, or pruritus (three RCTs, 288 patients) and similar 30-day mortality (five RCTs, 498 patients).

2. Compared with polyethylene-made stents, Teflon-made stents provide significantly less short-term success (three RCTs, 278 patients) but similar morbidity and 30-day mortality (five RCTs, 441 patients) [10].

Teflon-made stents (with or without sideholes) proved in RCTs to present more drainage failures compared with polyethylene stents (stent migration was more frequent with Teflon-made stents in one study; reason for failure was not investigated in a majority of patients in another RCT) [20-22].

Four RCTs compared various SEMS models, including covered and uncovered Wallstents and Ultraflex Diamond stents, Luminex, Hanaro, Zilver, and spiral Z stents [23-26]; none of these RCTs reported a significant difference in short-term efficacy of SEMSs. Symptoms that may improve after biliary stenting include pruritus, jaundice, anorexia, asthenia, sleep pattern, and diarrhea [27]. In two prospective studies, only a minority of the domains of quality of life that were investigated using validated questionnaires had significantly improved 4 weeks after stent insertion (drop-out rates were high at $19 \%$ and $48 \%$ ) [28,29]. One of these studies found: (i) that improvements were less important in patients with a baseline bilirubin $>13 \mathrm{mg} / \mathrm{dL}$, and (ii) that hyperbilirubinemia decreased after stent insertion by at least $20 \%$ at day 7 in $78 \%$ of patients [28]. Another study found that $76 \%$ of patients achieved a post stenting bilirubin level of $\leq 2 \mathrm{mg} / \mathrm{dL}$ [30]. Failures to achieve this level were associated with a high baseline bilirubin level, particular features of biliary stricture (multifocal or located outside of the CBD), diffuse liver metastases, and INR of $\geq 1.5$. The authors recommended endoscopic revision in patients who fail to achieve a bilirubin level of $\leq 2 \mathrm{mg} / \mathrm{dL}$, after 3 weeks if the pre-stenting bilirubin level was $<10 \mathrm{mg} / \mathrm{dL}$, or after 6 weeks if the pre-stenting level was $\geq 10 \mathrm{mg} / \mathrm{dL}$.

\section{Long-term stent efficacy for palliation of malignant common bile duct (CBD) obstruction \\ $\nabla$}

For palliation of malignant CBD obstruction, endoscopic biliary drainage is effective in $>80 \%$ of cases (Evidence level $1++$ ), with lower morbidity than surgery (Evidence level $1+$ ). SEMSs present a lower risk of recurring biliary obstruction than single plastic stents, without difference in patient survival, at least if patients are regularly followed up (Evidence level 1+). Initial insertion of a plastic stent is most cost-effective if patient life expectancy is shorter or than 4 months; if it is longer than 4 months then initial insertion of a SEMS is more cost-effective (Evidence level 2+). Amongst SEMS models measuring $10 \mathrm{~mm}$ in diameter, no difference has been clearly demonstrated, including between covered and uncovered models. Amongst plastic stents, those measuring $10 \mathrm{Fr}$ in diameter, and possibly some stent designs (i.e., DoubleLayer and stents equipped with an antireflux valve), provide the longest biliary patency; drug administration does not prolong stent patency (Evidence level $1+$ ).

Palliative drainage of malignant CBD obstruction should be first attempted endoscopically (Recommendation grade A). Initial insertion of a 10-Fr plastic stent is recommended if the diagnosis of ma- 
lignancy is not established or if expected survival is $<4$ months (Recommendation grade $C$ ). No drug prescription is recommended to prolong stent patency (Recommendation grade A). In patients with an established diagnosis of malignancy, initial insertion of a 10-mm diameter SEMS is recommended if expected survival is $>4$ months (or if SEMS cost is $<50 \%$ that of ERCP). Amongst biliary SEMSs, a model that is economical and with which the endoscopist has personal experience is recommended (Recommendation grade C).

A meta-analysis of three RCTs including 308 patients in total has compared endoscopic vs. surgical biliary drainage in patients with pancreatic cancer [31]. No differences in terms of technical success, therapeutic success, survival, or quality of life were found. Nevertheless, the relative risk of all complications was reduced by $40 \%(\mathrm{P}<0.001)$ and there was a trend for a lower 30-day mortality rate $(P=0.07)$ in the endoscopy group. Biliary obstruction recurred more frequently in the endoscopy compared with the surgical group $(\mathrm{P}<0.001)$ but plastic stents were used. A single RCT compared surgery vs. SEMS for biliary drainage in 30 patients with pancreatic cancer, with no differences between groups except a better quality of life at 30 days and a lower total cost in favor of the endoscopic treatment [32].

For the comparison of plastic stents vs. SEMSs, a meta-analysis (seven RCTs including a total of 724 patients with a malignant distal biliary obstruction) showed that the risk of recurring biliary obstruction was halved with SEMSs compared with plastic stents, both at 4 months and until patient death/end-of-study [33]. Another meta-analysis included slightly different RCTs and reached similar conclusions [10]. The median patency of $10-\mathrm{Fr}$ plastic stents has been estimated at 4-5 months and no significant differences were reported for patient survival [10,33]. However, based on a retrospective study, it has been suggested that outside of the strict follow-up of RCTs, survival could be prolonged with stents that provide longer biliary patency [34]. With regard to cost-effectiveness, a decision analysis model showed that, for the endoscopic drainage of malignant non-hilar biliary obstruction, initial insertion of a SEMS is most cost-effective if patient life expectancy is longer than 4 months or if SEMS cost is $<50 \%$ that of ERCP, but otherwise initial insertion of a plastic stent is most economical [35]. However, a retrospective study where SEMS cost was four times that of ERCP found that the cost of biliary drainage using SEMSs or plastic stents was similar and that patients treated with SEMSs had shorter hospital stays [36].

For the comparison of plastic stent models, the stent diameter is critical: 10-Fr models provide longer biliary patency compared with thinner ones (11.5-Fr models do not provide longer patency) [37-40]. A Tannenbaum stent design (i.e., without sideholes) was suggested to provide longer biliary patency than a standard model in a nonrandomized study [41]; this was not confirmed in RCTs $[20,42]$. Additional modifications to the Tannenbaum design (i.e., use of a specific material for the DoubleLayer stent [Olympus, Tokyo, Japan] or addition of an antireflux valve [Wilson-Cook, Winston-Salem, NC, USA]) were found to prolong biliary patency relative to standard Tannenbaum design in single RCTs that require confirmation $[43,44]$. Another possibility to prolong biliary patency could be to insert multiple plastic stents (only one of 22 patients [ $4.5 \%$ ] had relapsing biliary obstruction with multiple stents left in place for a median of 242 days in a retrospective study) [45]. With polyethylene biliary stents, ursodeoxycholic acid and antibiotics are ineffective to prevent stent dysfunction; patency duration decreases with increasing numbers of stent exchanges [46,47].

For the comparison of covered vs. uncovered SEMSs, three RCTs showed contradictory results: longer patency with a noncommercially available covered model in 112 patients (one RCT) and no difference with a commercially available model in 529 patients (two RCTs) $[23,48,49]$. For the comparison of different models of uncovered SEMSs, three RCTs compared six SEMS models in 465 patients [24-26]; the single factor that was associated with a shorter patency duration was a smaller (6-mm) stent diameter [25].

\section{Indications for stenting and stent selection in patients with a potentially resectable CBD obstruction $\nabla$}

In patients with a resectable malignant CBD stricture, insertion of a plastic biliary stent followed by delayed surgery is associated with a higher morbidity compared with surgery at 1 week (Evidence level $1++$ ). Some models of biliary SEMSs (short intrapancreatic or covered) do not impede pancreatic resection and may be used for preoperative biliary drainage in patients with malignant CBD obstruction whose surgical status is uncertain (Evidence level 2+).

We recommend preoperative drainage of potentially resectable malignant CBD obstruction only in patients who are candidates for neoadjuvant therapies, in patients with acute cholangitis, or in patients with intense pruritus and delayed surgery (Recommendation grade A). Plastic as well as short, intrapancreatic or covered SEMSs may be used, with a preference for SEMSs in patients who are candidates for neoadjuvant therapies (Recommendation grade C).

In patients with a malignant CBD obstruction scheduled for surgical resection, two RCTs have shown that overall morbidity was increased if plastic biliary drains were placed preoperatively compared with direct surgery $[50,51]$. These results are in line with a meta-analysis of four RCTs that compared preoperative percutaneous biliary drainage with direct surgery in similar indications [52]. Nevertheless, if for any reason an ERCP is performed for diagnostic purposes, drainage must be provided to prevent cholangitis [53].

If patient surgical status is uncertain when endoscopic biliary drainage is performed, short or covered SEMSs are as cost-effective as plastic stents to drain a biliary obstruction related to a pancreatic cancer (the difference in costs is approximately $1 \%$ ) $[54,55]$. This is related to the facts that: (i) only a minority of patients with a pancreatic cancer actually undergo resection (hence the longer patency of SEMSs vs. plastic stents is beneficial in a majority of patients), and (ii) if resection is performed, it is not hindered by a short intrapancreatic SEMS or a covered SEMS.A potential benefit of SEMS over plastic stents in these conditions is the lower incidence of stent-related complications as suggested by retrospective case-controlled studies $[56,57]$.

In patients with an uncertain diagnosis at the time of biliary drainage, a plastic stent is preferred to avoid long-term complications of SEMSs in benign strictures [58]. Ideally, EUS staging should be performed before biliary drainage as T staging may be inaccurate in the presence of a biliary stent $[59,60]$. 


\section{Complications of biliary stenting}

\subsection{Early complications}

Early complications develop in approximately $5 \%$ of patients after attempted endoscopic biliary stenting and are not related to the type of stent used (Evidence level $1++$ ). The reader is referred to other guidelines for detailed recommendations about the prevention of infection, pancreatitis, and bleeding.

Early complications were reported in $4.9 \%$ of 638 patients included in RCTs that compared various stent models for the endoscopic drainage of malignant CBD obstruction [20-22,42,6164]. Complications were distributed as follows: biliary infection (35\%), pancreatitis (29\%), bleeding (23\%), perforation (6\%), early stent migration and renal failure (3\% each). Complication rates were not different between stent models in a meta-analysis of RCTs [33].

Post-ERCP biliary infection is a serious complication that is fatal in $8 \%-20 \%$ of cases and is best prevented by complete biliary drainage $[53,65]$. Recent guidelines recommend routine antibiotic prophylaxis in selected patients (with liver transplant, or severe neutropenia, advanced hematological malignancy, or anticipated incomplete biliary drainage) and a full antibiotic course if adequate biliary drainage is not achieved during the procedure [65].

Post-ERCP pancreatitis is usually mild but it may rarely be fatal. Recent ESGE guidelines recommended periprocedural rectal administration of nonsteroidal anti-inflammatory drugs for procedures at low risk of post-ERCP pancreatitis and consideration of prophylactic pancreatic stent placement in high risk conditions, including precut biliary sphincterotomy, pancreatic guidewireassisted biliary cannulation and simultaneous presence of several risk factors for post-ERCP pancreatitis [66,67]. These measures have not yet been largely adopted in the endoscopy community [68].

Bleeding is associated with sphincterotomy, not with biliary stenting [69]; it is made more likely by coagulation disorders but not by aspirin or by nonsteroidal anti-inflammatory drugs [70]. If sphincterotomy is envisaged, patients with a clinical history suggestive of a bleeding disorder (as is frequently the case in patients subjected to biliary stenting) should undergo testing of platelet count and prothrombin time [71]; these parameters should be managed to obtain adequate values during sphincterotomy, and blended current should be used $[11,70,72]$.

\subsection{Late complications}

Late complications of biliary stenting mostly consist of stent dysfunction, which is approximately twice as frequent with plastic stents compared with SEMSs, and, much less frequently, cholecystitis, duodenal perforation, and bleeding ulcer (Evidence level 1+).
- Table 2 summarizes the incidence of the most frequent late complications of biliary stenting. Rare complications (e.g., duodenal perforation, bleeding ulcer) were mostly described in case reports. Causes of stent dysfunction vary according to the type of stent; with fully covered SEMS, prospective studies are sparse and design modifications to prevent migration (flared ends, anchoring fins) are being tested.

\subsubsection{Stent dysfunction}

8.2.1.1 Stent migration Approximately 5\% of plastic stents and partially covered SEMSs migrate while 1\% of uncovered SEMSs and $20 \%$ of fully covered SEMSs migrate. After distal migration, most plastic stents are spontaneously eliminated. (Evidence level $1+$ ). Migration of plastic stents is more frequent in benign as compared with malignant biliary strictures, and with single as compared with multiple stents. Endoscopic treatment of stent migration is feasible in $>90 \%$ of cases with low morbidity (Evidence level $2+$ ). In patients with migrated stents, we recommend ERCP for removing stents that have not been spontaneously eliminated and for stenting potentially persistent strictures. In the case of persistent biliary stricture, we recommend inserting multiple plastic stents or, if a SEMS is indicated, an uncovered model (Recommendation grade $C$ ).

According to a retrospective study, risk factors for plastic stent migration include bridging of a benign biliary stricture and insertion of a single stent [73]. After distal migration, most plastic stents are spontaneously eliminated although bowel perforation (mostly in the duodenum) may exceptionally occur. In contrast to plastic stents, covered SEMSs are rarely eliminated spontaneously after distal migration (two of 36 patients in a recent series) [74].

Regarding treatment, proximally migrated plastic stents or SEMSs may be retrieved with a success rate $>90 \%$ using techniques described in the associated ESGE Technology Review [1]; no complications were reported in the few trials that mentioned this outcome [75 - 77]. If a SEMS cannot be extracted, its distal extremity can be trimmed in the case of distal migration or, in the case of proximal migration with a persistent stricture, a second SEMS can be inserted within the first one [1].

8.2.1.2. Stent occlusion Stent occlusion is caused by sludge (in plastic stents) or by tissue ingrowth/overgrowth or sludge (in SEMSs) (Evidence level 1-). Endoscopic restoration of biliary patency is successful in $>95 \%$ of patients with stent obstruction and exceptionally gives rise to complications (Evidence level $2+$ ). For occluded SEMSs, mechanical SEMS cleansing is poorly effective for restoring biliary patency; inserting a second SEMS within the occluded SEMS yields a longer biliary patency than inserting a plastic stent, particularly if one of the two SEMSs (initially placed or placed for treating stent dysfunction) is a covered model (Evidence level 2-).

\begin{tabular}{|lllll|}
\hline Complication & $\begin{array}{l}\text { Plastic stent } \\
(\mathbf{n = 8 2 5 )}\end{array}$ & $\begin{array}{l}\text { Uncovered SEMS } \\
(\mathbf{n = 7 2 4 )}\end{array}$ & $\begin{array}{l}\text { Partially covered SEMS } \\
(\mathbf{n = 1 1 0 7 )}\end{array}$ & $\begin{array}{l}\text { Fully covered SEMS } \\
\text { (n= 81) }\end{array}$ \\
\hline Stent dysfunction & $41 \%$ & $27 \%$ & $20 \%$ & $20 \%$ \\
\hline - Migration & $6 \%$ & $1 \%$ & $7 \%$ & $17 \%$ \\
\hline - Clogging & $33 \%$ & $4 \%$ & $6 \%$ & $7 \%$ \\
\hline - Tissue ingrowth & Not applicable & $18 \%$ & $7 \%$ & Not reported \\
\hline - Tissue overgrowth & Not applicable & $7 \%$ & $5 \%$ & Not reported \\
\hline Cholecystitis & $<0.5 \%$ & $1 \%$ & $4 \%$ & Not applicable 2 \\
\hline
\end{tabular}

Table 2 Stent-related complications in selected randomized controlled trials and single-arm prospective studies (for details see Appendix e3, available online). ${ }^{1}$

SEMS, self-expandable metal stent.

${ }^{1}$ Some patients concomitantly had different causes of stent dysfunction.

2 Most patients had biliary strictures complicating liver transplantation and no gallbladder in situ or a plastic stent inserted into the gallbladder when the cystic duct was covered by the SEMS. 
We recommend ERCP in patients with biliary stent occlusion, except when this is considered futile in patients with advanced malignant disease. Plastic stents should be exchanged for plastic (single or multiple) stents or a SEMS, according to the criteria stated above. Occlusion of biliary SEMSs should be treated by inserting a second SEMS within the occlusion (a covered model should be selected if the first SEMS was uncovered) or, in the case of a life expectancy $\leq 3$ months, by inserting a plastic stent (Recommendation grade $C$ ).

In patients with stent occlusion, ERCP successfully restores biliary patency in $>95 \%$ of patients and, in contrast to first stent insertion, it only rarely gives rise to complications [78-81]. Plastic stents present a median patency of 62-165 days; these stents may be exchanged prophylactically at scheduled intervals or when stent dysfunction develops [10]. Obstruction of biliary SEMSs is related to sludge deposition or tissue ingrowth/overgrowth. Five retrospective studies have reported the results of endoscopic treatment for SEMS occlusion in 216 patients [7882]. Three of these studies (involving 99 patients) tested SEMS cleansing as the only treatment for restoring biliary patency; they showed that it was poorly effective (median biliary patency following SEMS cleansing, $24-43$ days) [78-80]. The five studies also compared insertion of a plastic stent vs. insertion of a second SEMS within the occluded SEMS, with slightly divergent results: three studies reported a longer biliary patency with a second SEMS compared with a plastic stent (the difference was statistically significant in two studies $[79,81])$, and one study reported a longer biliary patency with a plastic stent inserted within the occluded SEMS [80]. The two most recent studies, also the largest, included 117 patients of whom 99 patients received a second SEMS to restore biliary patency $[81,82]$. Both of these studies showed that cumulative biliary patency was shorter in patients who had uncovered SEMS inserted at the first and second ERCP compared with those who had received at least one covered SEMS (in the largest study, survival was also significantly longer in these patients).

\subsubsection{Stent-related cholecystitis}

Neoplastic involvement of the cystic duct and gallbladder stones are the key risk factors for SEMS-related cholecystitis (Evidence level $2+$ ).

The risk of SEMS-related acute cholecystitis has recently been scrutinized because this complication has been reported in up to $10 \%$ of patients [ $83-86]$. Two large retrospective studies have found that tumor involvement of the cystic duct ostium, plus the presence of gallbladder stone in one study, but not the presence or absence of a covering on the SEMS are the main factors associated with post-ERCP cholecystitis $[85,87]$. Moreover, two RCTs comparing covered and uncovered SEMS in 529 patients did not find different rates of SEMS-induced cholecystitis $[48,49]$. However, some authors recommend inserting covered SEMS only in patients with previous cholecystectomy or below the cystic duct ostium. Prophylactic placement of a plastic stent in the gallbladder has been attempted but it may cause wire perforation or high rates of cholecystitis in the case of failed stent insertion [88]. Cholecystitis should be treated on a case-by-case basis by cholecystectomy or percutaneous gallbladder drainage in frail patients.

\section{Particular cases \\ $\nabla$}

\subsection{Hilar strictures}

In the case of malignant hilar stricture (MHS), assessment of tumor resectability by CT or MRI may be affected by the presence of biliary stents (Evidence level 2+). Resectability of MHS should be evaluated by imaging techniques in the absence of biliary stents (Recommendation grade $C$ ).

Multidetector-row CT and MRI are relatively accurate (75-90\%) in assessment of resectability of hilar tumors although they may underestimate ductal spread [89, 90]. Biliary stents create artifacts, reduce intrahepatic biliary dilatation and possibly cause periductal inflammation that may lead to misinterpretations at CT and MRI [91,92]. Reported experience of EUS staging of hilar malignancy is very limited because the technique is extremely demanding [93], although a new forward-viewing echoendoscope could facilitate the procedure [94].

In MHS of Bismuth-Corlette type $\geq 2$, better biliary drainage might be achieved with fewer infective complications by the percutaneous as compared with the endoscopic route (Evidence level 1-). Drainage by means of a combined endoscopic and percutaneous approach may be necessary to treat infective complications of MHS, especially in the setting of opacified and undrained intrahepatic biliary ducts. Endoscopic drainage of complex MHS more frequently fails in low volume vs. high volume centers (Evidence level 2-). Local expertise for percutaneous and endoscopic biliary drainage may not be available in many centers (Evidence level 1-). The choice between endoscopic or percutaneous drainage for MHS should be based on local expertise (Recommendation grade D); endoscopic drainage should be performed in high volume centers with experienced endoscopists and multidisciplinary teams (Recommendation grade $C$ ).

One debatable RCT and two retrospective studies compared endoscopic vs. percutaneous drainage of MHS using plastic or metal stents [95-97]. These studies included patients with strictures of Bismuth type $2 / 3$ [96], $3 / 4$ [97], and 2/3/4 [95]. They showed that percutaneous drainage of MHS has a higher success rate and a lower incidence of infective complications. The method of biliary drainage was not thoroughly detailed in any of these studies but biliary ducts were left opacified and undrained in all of them. This is no longer standard of care $[98,99]$. Noninfective complications (bleeding, pancreatitis) were more frequent in the percutaneous groups [95,97].

High volume hospitals have a higher success rate at ERCP than low volume hospitals [14]. Endoscopic stenting in MHS is considered to be an advanced procedure according to the modified Schutz's score [100]. Technical failure of endoscopic drainage of MHS is reported in up to $20 \%$ of cases [95, 96], and several studies stressed that drainage of complex MHS requires experienced endoscopists $[14,95,96]$. Prompt availability of percutaneous access in the immediate environment of the endoscopic unit is mandatory if the endoscopic route is selected, due to the high incidence of infective complications after attempted endoscopic biliary drainage and the much shorter survival reported after failure at initial drainage attempt, whatever the route [97].

MRI seems to be slightly more accurate than CT for assessing the level of obstruction in MHS; both methods allow measurement of the volume of liver lobes. This ductal and parenchymal information is useful for directing palliative drainage of MHS (Evidence level 2+). We recommend performance of MRI to assess the hepatobiliary anatomy before attempting drainage of MHS (Recommendation grade C). 
According to studies with limited sample size, MRI allows identification of the level and longitudinal extent of MHS with $90 \%$ accuracy [90, 101], as compared with $75 \%$ for multidetector-row CT [102]. Measurement of liver volumes by CT and MRI is similarly effective [103]. Information obtained by magnetic resonance cholangiography can help guiding endoscopic MHS drainage to limit infective complications [99, 104].

After bilateral biliary opacification upstream from MHS, morbidity and mortality rates are higher with unilateral compared with bilateral biliary drainage (Evidence level 2-). A low incidence of cholangitis has consistently been achieved when specific endoscopic techniques were used to target drainage to duct $(s)$ selected on the basis of MRI or CT (Evidence level $2+$ ). Draining $>50 \%$ of the liver volume is associated with higher drainage effectiveness and longer survival than draining $<50 \%$ of the liver volume (Evidence level 2-).

In MHS, the liver sector(s) to be drained should be selected before beginning ERCP, based on MRI or CT, with the aim of draining $>50 \%$ of the liver volume. Bile duct(s) unintentionally opacified upstream from an MHS should be drained during the same procedure. Antibiotics should be administered in case of anticipated incomplete biliary drainage and, if drainage proves to be incomplete, they should be continued until complete drainage is achieved (Recommendation grade $\mathrm{C}$ ).

In a recent retrospective study, endoscopic drainage of more than $50 \%$ of the liver volume in patients with MHS was independently associated with a greater decrease in the bilirubin level, a lower incidence of early cholangitis, and a longer patient survival than endoscopic drainage of less than $50 \%$ of the liver volume [105]. If contrast dye is injected upstream from an MHS into peripheral hepatic ducts that are not subsequently drained, cholangitis is extremely frequent $[98,106]$. To reduce the risk of cholangitis, endoscopic insertion of a single stent into the most accessible biliary system has been proposed for the palliation of MHS [107]. A low rate of post-procedure cholangitis $(0-6 \%)$ was observed in three single-arm prospective trials that used MRI or CT as a "road map" to enable injection and drainage of only the largest intercommunicating segmental ducts upstream from an MHS, using contrast-free duct cannulation or anterograde endoscopic duct opacification [104,108, 109].

Four studies that used the endoscopic $(n=3)$ or the percutaneous $(n=1)$ route for biliary drainage compared unilateral with bilateral drainage of MHS. A trend for a longer survival and a lower incidence of cholangitis was found after bilateral compared with unilateral drainage $[98,106,110,111]$. All of these studies present two biases, namely the inclusion of patients with Bismuth-Corlette type I MHS (one stent is enough to drain both liver lobes), and the use of inappropriate numbers of stents to drain the opacified intrahepatic ducts (bilateral drainage of Bismuth - Corlette type III or IV MHS leaves undrained ducts).

Antibiotic prophylaxis is recommended in patients with anticipated incomplete biliary drainage, and it should be continued in the case of incomplete biliary drainage [112].

Plastic stents and uncovered SEMSs yield similar short-term results in patients with MHS but SEMSs provide a longer biliary patency compared with plastic stents (only uncovered SEMSs are used in this setting to prevent occlusion of side branches) (Evidence level $1-)$. Plastic stenting is recommended as long as no definitive decision about curative/palliative treatment has been taken. If a decision for palliative treatment is taken, insertion of SEMSs is recommended in patients with life expectancy $>3$ months or with biliary infection (Recommendation grade $B$ ).
Only one RCT (using the percutaneous route) and one prospective observational study (using primarily the endoscopic route) have compared plastic stents with SEMSs for MHS drainage; they showed longer patency and less need for reintervention with SEMSs compared with plastic stents $[113,114]$. Endoscopic insertion of multiple SEMSs in MHS is technically demanding and is facilitated by new thinner SEMS delivery catheters and duodenoscopes with larger working channels $[1,115,116]$. Plastic stent insertion is recommended in MHS for which a decision for palliation has not been taken, because removal of uncovered SEMSs is usually not possible.

SEMSs do not impede light delivery for photodynamic therapy but adjustments of the light dose are required (Evidence Level 2++). Trans-SEMS photodynamic therapy for palliation of malignant hilar strictures should be administered in centers with well-trained personnel (Recommendation grade $D$ ).

Photodynamic therapy for unresectable hilar cholangiocarcinoma was shown to prolong survival in two RCTs that included patients treated with plastic stents, and also in a non-randomized controlled study that included patients treated with biliary SEMSs [117-119]. During photodynamic therapy, endoscopic light delivery requires temporary removal of plastic stents or, if biliary SEMSs have been inserted, adjustment of the light dose to compensate for reduced transmittance of light [120].

Stent dysfunction in patients with MHS is treated as follows: plastic stents are removed, ducts are cleaned and new stents are inserted; uncovered SEMSS are cleaned and, in the case of persistent stricture, new stents are inserted. The choice between plastic stents or SEMSs for re-stenting is based on the degree of biliary infection and the life expectancy (Recommendation grade D).

Dysfunction of plastic stents in MHS is treated by stent removal followed by cleaning of debris from the duct and insertion of a new stent. Re-insertion of a stent into the duct previously stented may be facilitated by stent removal "over the guidewire." In the presence of thick bile/pus, insertion of a SEMS (or a nasobiliary drain that allows for repeated flushing) can be considered, to avoid the early clogging that may occur with a plastic stent. Uncovered SEMSs cannot be removed from a few days after insertion. Depending on the cause of the SEMS dysfunction, treatment consists of removal of debris from the SEMS lumen or insertion of a new stent. To facilitate SEMS cannulation in patients with multiple SEMSs, these stents are best positioned with their distal extremity in the duodenum or, if they are side-by-side in the CBD, at exactly the same level in the CBD [121].

\subsection{Benign strictures}

In the case of benign CBD strictures, temporary simultaneous placement of multiple plastic stents is technically feasible in $>90 \%$ of patients; it is the endoscopic technique that provides the highest long-term biliary patency rate ( $90 \%$ for postoperative biliary strictures and 65\% for those complicating chronic pancreatitis); it requires a mean of approximately four ERCPs over a 12-month period. Possible stricture recurrences after this treatment are usually successfully re-treated by ERCP. Temporary placement of single plastic stents provides poorer patency rates; treatment with uncovered SEMSs is plagued by a high long-term morbidity; temporary placement of covered SEMSs is an investigational option that needs to be carefully evaluated by long-term follow-up studies (Evidence level $1+$ ).

In patients with benign CBD strictures, we recommend temporary placement of multiple plastic stents provided that the patient consents and is thought likely to be compliant with repeat interven- 
tions. The insertion of uncovered biliary SEMSs is strongly discouraged (Recommendation grade A). Covered SEMSs are a promising alternative for selected benign CBD strictures. Because of the risk of fatal septic complications, a recall system should be set up for the care of patients who do not present for ERCP at scheduled dates (Recommendation grade D).

Benign biliary strictures for which endoscopic treatment is proposed are mostly related to liver transplantation or chronic pancreatitis (one third of cases each) and, less frequently, to other causes (e.g., cholecystectomy, sphincterotomy); about $85 \%$ of these strictures are located at the level of the CBD [122]. Strictures related to chronic pancreatitis are the most difficult to treat, in particular if calcifications are present in the pancreatic head: they recur in approximately one third of patients after temporary insertion of multiple plastic stents simultaneously or of covered SEMSs, and in two thirds of cases after temporary dilation using a single plastic stent [123-126].

Systematic reviews of stenting for benign biliary strictures showed that: (i) clinical success was most frequently observed with temporary simultaneous placement of multiple plastic stents (94\%), followed by placement of uncovered SEMSs ( $80 \%$ ), and by placement of a single plastic stent (60\%); (ii) complications were more frequent with uncovered SEMSs (40\%) compared with single plastic stents (36\%) and multiple plastic stents (20 $\%$ ); (iii) the patency of uncovered biliary SEMSs sharply decreased over time from 1 year after SEMS insertion; (iv) management of late occlusion of uncovered biliary SEMS frequently necessitated surgery, percutaneous drainage, or unconventional endoscopic procedures (e.g., brachytherapy) [58, 122].

- Table 3 summarizes the treatment of benign biliary strictures with temporary simultaneous placement of multiple plastic stents in eight series, of which three were prospective $[123,127$, 128 ]. Long-term success was $\geq 85 \%$ except in two series that included patients with strictures related to chronic pancreatitis. Possible stricture recurrence after treatment with multiple plastic stents has usually been successfully re-treated with ERCP $[129,130]$. Stent exchange was scheduled at 3-month intervals in most series but a retrospective comparative study found that cholangitis was similarly rare in patients with exchange of multiple plastic biliary stents scheduled within 6 months $(n=52)$ compared with 6 months or longer after placement $(n=22)$ [45]. Other authors have attempted to shorten stenting duration by exchanging stents with a higher number of stents every 2 weeks, with $87 \%$ success at 1 year post stent removal [128]. As some models of covered SEMSs may consistently be extracted, temporary insertion of a fully covered SEMS is attractive for achieving a dilation of large diameter in a single ERCP procedure [131 - 133]. However, limitations of this technique are emerging [134].

In patients with chronic pancreatitis and alcohol abuse, compliance with stent exchange is problematic: in two series involving 43 patients, $70 \%$ of patients had stent-related complications (fatal in $5 \%$ of cases) because they did not present for scheduled stent exchanges [125, 135]. Hepaticojejunostomy remains a valid option for noncompliant patients with alcoholic chronic pancreatitis or if the stricture does not respond to multiple plastic stenting.

- Table4 summarizes the treatment of benign biliary strictures with temporary placement of covered SEMSs. Two studies enrolled patients with heterogeneous benign strictures and did not have a detailed subgroup analysis $[133,136]$. Similar success rates for SEMS removal were reported with fully covered and partially covered models, except in a small study that reported a low suc- cess rate with fully covered SEMSs [137]. The rate of immediate resolution for benign biliary strictures after covered SEMS removal ( $80 \%)$ seems promising. Nevertheless, at short-term follow-up ( $<2$ years), persistent stricture resolution was reported in only $50-80 \%$ of patients with benign biliary strictures related to chronic pancreatitis and to orthotopic liver transplant [75, $131,132,137]$. Very few data are available about the treatment of postoperative biliary strictures with covered SEMSs. Therefore, the use of covered SEMSs to treat benign biliary strictures should be reserved to clinical trials that aim to identify the type of stent and of stricture associated with the greatest long-term benefit from this treatment.

\subsection{Bile leaks}

In the absence of transection of the $C B D$, endoscopic treatment (biliary sphincterotomy or temporary drainage associated with removal of any potentially associated biliary obstacle) allows healing of more than $90 \%$ of biliary leaks. Biliary stenting provides faster leak resolution than sphincterotomy alone; it is equally effective whether sphincterotomy is performed or not. Biliary sphincterotomy is associated with a risk of short-term and long-term complications, particularly in young patients (Evidence level 1+). In the case of temporary biliary stenting, biliary abnormalities (mostly sludge, stones, or persistent leak) can be found at the time of stent removal in a significant proportion of patients (Evidence level 2-). We recommend discussing the advantages and inconveniences of available treatment options with the patient before ERCP (e.g., the need for repeat ERCP in the case of stenting). At ERCP, one should pay particular attention to locating the leak and to detection of potentially associated biliary lesions or obstacles (e.g., retained stone) that require specific treatment. In the absence of such lesions, we recommend insertion of a plastic biliary stent without performance of sphincterotomy, and removal of the stent 4 to 8 weeks later. Endoscopic sphincterotomy alone is an alternative option, in particular in elderly patients (Recommendation grade B). At the time of stent removal, cholangiography and duct cleansing should be performed (Recommendation grade $D$ ).

Bile leaks are most often a consequence of surgery (cholecystectomy, liver transplantation, and major liver surgery) or other trauma. Endoscopic treatment is most often effective except in the case of biliary transection; it aims to suppress the pressure gradient between the biliary tree and the duodenum to promote preferential bile flow into the duodenum and to allow for leak sealing. This can be achieved through biliary stenting, biliary sphincterotomy, or nasobiliary drainage, with the two latter options precluding the need for repeat ERCP. Biliary sphincterotomy may be associated with short-term and long-term complications in $15 \%$ of cases [140].

Sandha et al. have proposed an algorithm in which biliary sphincterotomy was performed to treat mild leaks (i.e., requiring intrahepatic duct filling to identify the leak), and temporary biliary stenting (4-6 weeks) was done for severe leaks or in case of stricture, contraindication to sphincterotomy, or inadequate drainage of contrast medium after sphincterotomy [141]. This strategy yielded satisfactory results in $>90 \%$ of 207 consecutive patients. Two prospective studies involving 56 patients in total showed that, in the absence of biliary stricture, sphincterotomy (associated with stone extraction if applicable) was followed by bile leak sealing in approximately $90 \%$ of patients; in one study, healing was delayed at a mean of 11 days [142,143]. An RCT in dogs showed that biliary stenting allowed post-cholecystectomy cystic leaks to seal more rapidly than did biliary sphincterotomy [144]. 


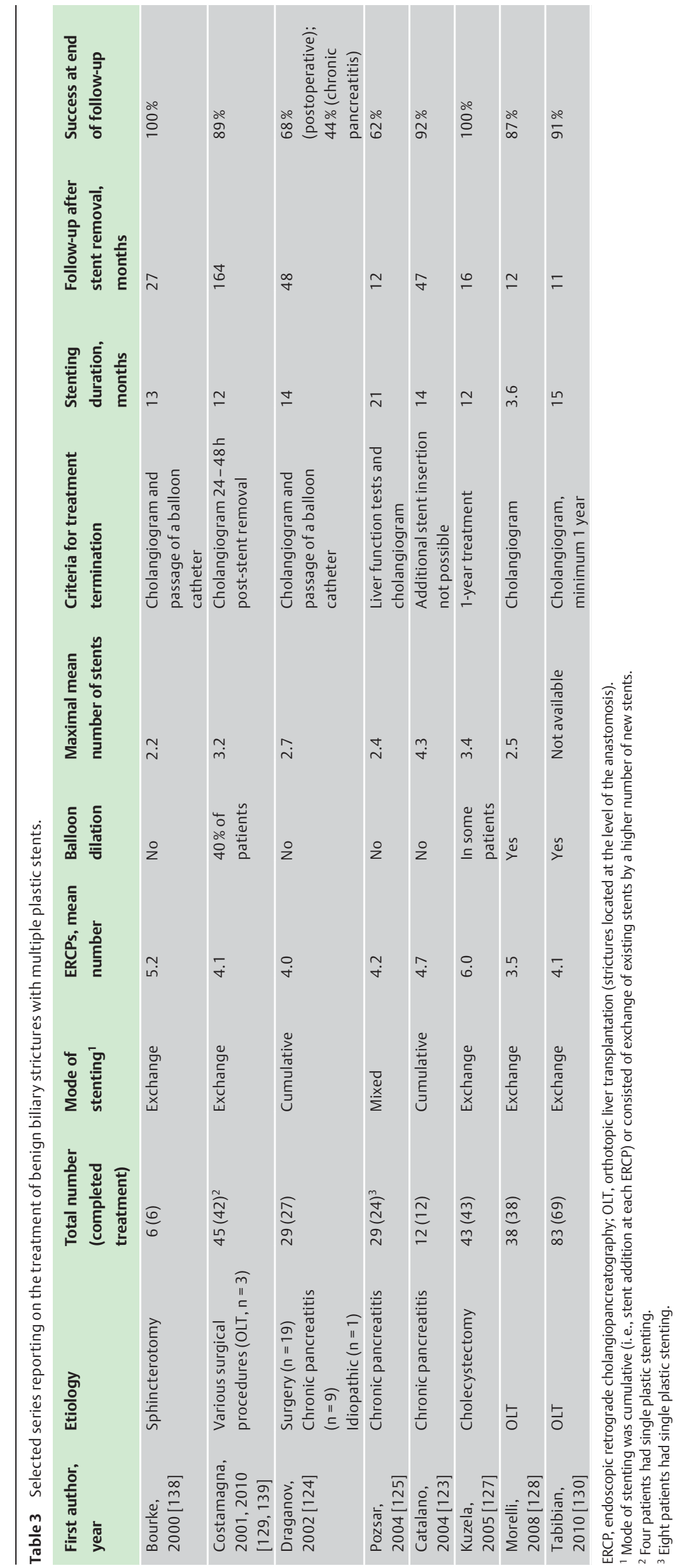




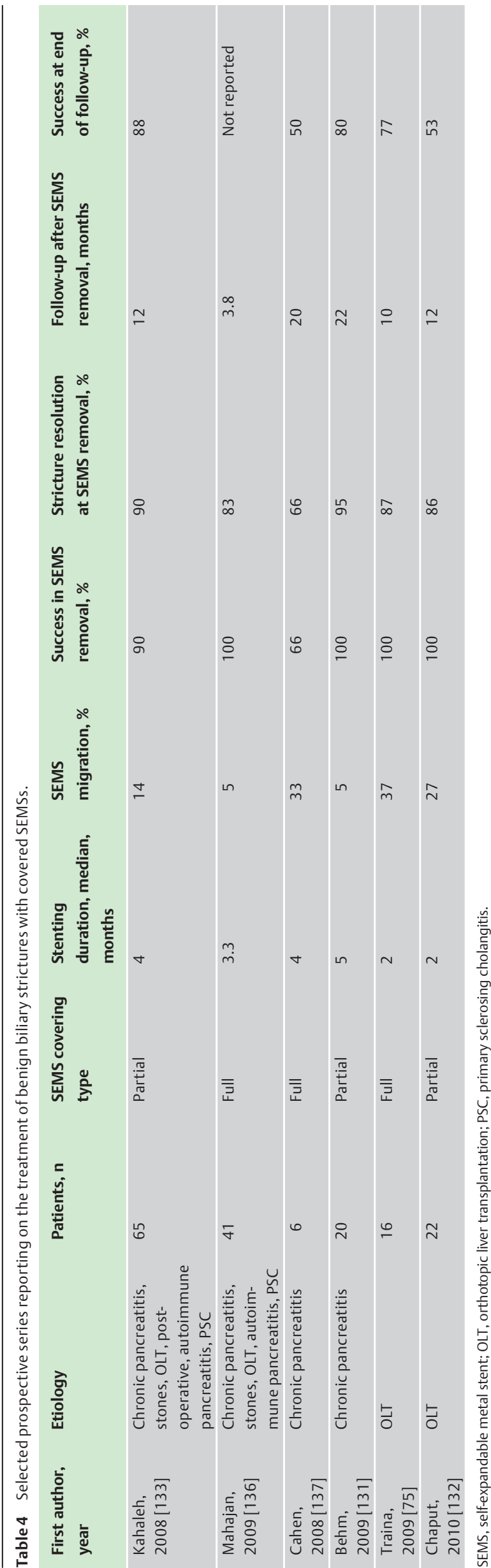

Various strategies of biliary stenting yielded similar results in two RCTs (globally, 112 of 115 patients [97\%] had successful treatment): one RCT compared 4-week stenting using either a $10-\mathrm{Fr}$ or a 7-Fr stent (after biliary sphincterotomy) [145]; the other RCT compared biliary drainage using either a 7-Fr stent without biliary sphincterotomy or a $10-\mathrm{Fr}$ stent with biliary sphincterotomy [8].

A large retrospective study found abnormalities in approximately one fourth of patients at cholangiography performed after removal of stents inserted for post-cholecystectomy bile leaks [146]. These consisted of CBD sludge or stones as well as persistent bile leaks. Therefore, cholangiography with a balloon sweep is preferred over a simple duodenoscopy for removing the biliary stent.

\subsection{Temporary stenting for biliary stones}

In patients with irretrievable biliary stones, insertion of a plastic stent is effective in the short term to drain the bile ducts; it is frequently associated with partial (or even complete) stone dissolution that facilitates delayed endoscopic stone removal in most cases (Evidence level 1-). Addition of oral ursodeoxycholic acid does not increase the stone dissolution rate (Evidence level 1-) but a combination of oral ursodeoxycholic acid and terpene could be more effective (Evidence level 2-). Morbidity/mortality is high in the case of long-term biliary stenting (Evidence level 1+).

If ERCP fails to remove difficult biliary stones or is contraindicated, temporary (e.g., 3-month) plastic stenting should be considered. After biliary stent placement, the patient and referring physicians should be warned that, when used as a long-term measure, biliary stent placement is associated with a high risk of cholangitis (Recommendation grade B). Addition of oral ursodeoxycholic acid associated with terpene should be considered (Recommendation grade $D$ ).

Biliary stone extraction using standard techniques fails in $5-10 \%$ of cases, necessitating the use of lithotripsy or large-balloon biliary dilation. If these techniques fail or cannot be used (e.g., because of dual antiplatelet agents therapy that cannot be discontinued) [70], biliary stenting is a quick alternative option. It is effective for draining the bile ducts and it is associated with partial or complete stone dissolution in $>50 \%$ of cases, facilitating subsequent extraction [147-149]. Stenting should be temporary only as complications (including death in up to 6.7-16\%) are frequent during long follow-up (34-40\%) [150]. In one prospective study that included 20 patients, it has been suggested that double-pigtail stents of 7-Fr with the proximal pigtail wrapped around the stone ensured more effective lithotripsy (complete or partial stone dissolution was noted in $70 \%$ of the patients at second ERCP 6 months later) [151]. Similar findings were reported in a more recent retrospective study of 40 patients [152].

Addition of oral ursodeoxycholic acid to biliary stenting was shown in an RCT to be ineffective for improving stone dissolution [153]. Two uncontrolled studies have suggested that addition of oral ursodeoxycholic acid plus a terpene preparation to biliary stenting might increase the stone dissolution rate [149,154].

\section{Use of the guideline}

ESGE guidelines represent a consensus of best practice based on the available evidence at the time of preparation. They may not apply in all situations and should be interpreted in the light of specific clinical situations and resource availability. Further con- 
trolled clinical studies may be needed to clarify aspects of these statements, and revision may be necessary as new data appear. Clinical consideration may justify a course of action at variance to these recommendations. ESGE guidelines are intended to be an educational device to provide information that may assist endoscopists in providing care to patients. They are not rules and should not be construed as establishing a legal standard of care or as encouraging, advocating, requiring, or discouraging any particular treatment.

Competing interests: Guido Costamagna, René Laugier, and Jacques Devière have received research support from Cook Endoscopy Inc., Limerick, Ireland, and from Boston Scientific, Natick, Massachusetts, USA.

\section{Institutions}

${ }^{1}$ Service of Gastroenterology and Hepatology, Geneva University Hospitals, Geneva, Switzerland

2 Digestive Endoscopy Unit, Catholic University, Rome, Italy

${ }^{3}$ Department of Gastroenterology and Hepato-Pancreatology, Erasme

University Hospital, Brussels, Belgium

${ }^{4}$ Department of Hepato-Gastroenterology. La Timone Hospital Marseilles

France

${ }^{5}$ Digestive and Bronchial Endoscopy Unit, Cannes Hospital, Cannes, France

\section{References}

1 Dumonceau JM, Heresbach D, Deviere J et al. Biliary stents: models and methods for endoscopic stenting. European Society of Gastrointestinal Endoscopy (ESGE) Technology Review. Endoscopy 2011; 43: 617-626

2 Dumonceau JM, Riphaus A, Aparicio JR et al. European Society of Gastrointestinal Endoscopy, European Society of Gastroenterology and Endoscopy Nurses and Associates, and the European Society of Anaesthesiology Guideline: Non-anesthesiologist administration of propofol for GI endoscopy. Endoscopy 2010; 42: 960-974

3 Dumonceau J-M, Polkowski M, Larghi A et al. Indications, results and clinical impact of EUS-guided sampling in Gastroenterology: ESGE Clinical Guideline. Endoscopy 2011; 43: 1-16

4 Harbour R, Miller J. A new system for grading recommendations in evidence based guidelines. BMJ 2001; 323: $334-336$

5 Artifon ELA, Sakai P, Ishioka $S$ et al. Endoscopic sphincterotomy before deployment of covered metal stent is associated with greater complication rate: a prospective randomized control trial. J Clin Gastroenterol 2008; 42: 815-819

6 Giorgio PD, Luca LD. Comparison of treatment outcomes between biliary plastic stent placements with and without endoscopic sphincterotomy for inoperable malignant common bile duct obstruction. World J Gastroenterol 2004; 10: 1212 - 1214

7 Hui C-K, Lai K-C, Yuen M-F et al. Does the addition of endoscopic sphincterotomy to stent insertion improve drainage of the bile duct in acute suppurative cholangitis? Gastrointest Endosc 2003; 58: 500 504

8 Mavrogiannis C, Liatsos C, Papanikolaou IS et al. Biliary stenting alone versus biliary stenting plus sphincterotomy for the treatment of postlaparoscopic cholecystectomy biliary leaks: a prospective randomized study. Eur J Gastroenterol Hepatol 2006; 18: 405-409

9 Banerjee N, Hilden K, Baron TH et al. Endoscopic biliary sphincterotomy is not required for transpapillary SEMS placement for biliary obstruction. Dig Dis Sci 2011; 56: $591-595$

10 Moss AC, Morris E, Mac Mathuna P. Palliative biliary stents for obstructing pancreatic carcinoma. Cochrane Database Syst Reviews 2006: 02 CD004200. Updated March 2009

11 Rey JF, Beilenhoff U, Neumann CS et al. European Society of Gastrointestinal Endoscopy (ESGE) guideline: the use of electrosurgical units. Endoscopy 2010; 42: 764-772

12 Tringali A, Mutignani M, Milano A et al. No difference between supine and prone position for ERCP in conscious sedated patients: a prospective randomized study. Endoscopy 2008; 40: 93-97

13 Williams EJ, Taylor S, Fairclough P et al. Are we meeting the standards set for endoscopy? Results of a large-scale prospective survey of endoscopic retrograde cholangio-pancreatograph practice. Gut 2007; 56: $821-829$
14 Varadarajulu S, Kilgore ML, Wilcox CM et al. Relationship among hospital ERCP volume, length of stay, and technical outcomes. Gastrointest Endosc 2006; 64: 338 - 347

15 Raymondos K, Panning B, Bachem I et al. Evaluation of endoscopic retrograde cholangiopancreatography under conscious sedation and general anesthesia. Endoscopy 2002; 34: $721-726$

16 Etzkorn KP, Diab F, Brown RD et al. Endoscopic retrograde cholangiopancreatography under general anesthesia: indications and results. Gastrointest Endosc 1998; 47: 363-367

17 Ramirez FC, Dennert B, Sanowski RA. Success of repeat ERCP by the same endoscopist. Gastrointest Endosc 1999; 49: 58 -61

18 Choudari CP, Sherman S, Fogel EL et al. Success of ERCP at a referral center after a previously unsuccessful attempt. Gastrointest Endosc 2000; 52: $478-483$

19 Maranki J, Hernandez AJ, Arslan B et al. Interventional endoscopic ultrasound-guided cholangiography: long-term experience of an emerging alternative to percutaneous transhepatic cholangiography. Endoscopy 2009; 41: $532-538$

20 England RE, Martin DF, Morris J et al. A prospective randomised multicentre trial comparing $10 \mathrm{Fr}$ Teflon Tannenbaum stents with $10 \mathrm{Fr}$ polyethylene Cotton-Leung stents in patients with malignant common duct strictures. Gut 2000; 46: 395-400

21 van Berkel A-M, Huibregtse IL, Bergman JJGHM et al. A prospective randomized trial of Tannenbaum-type Teflon-coated stents versus polyethylene stents for distal malignant biliary obstruction. Eur J Gastroenterol Hepatol 2004; 16: 213-217

22 van Berkel AM, Boland C, Redekop WK et al. A prospective randomized trial of Teflon versus polyethylene stents for distal malignant biliary obstruction. Endoscopy 1998; 30: 681 -686

23 Isayama $\mathrm{H}$, Komatsu $Y$, Tsujino $T$ et al. A prospective randomised study of "covered" versus "uncovered" Diamond stents for the management of distal malignant biliary obstruction. Gut 2004; 53: 729-734

24 Katsinelos P, Kountouras J, Paroutoglou G et al. Uncovered Hanaro versus Luminex metal stents for palliation of malignant biliary strictures. Clin Gastroenterol 2008; 42: 539-545

25 Loew BJ, Howell DA, Sanders MK et al. Comparative performance of uncoated, self-expanding metal biliary stents of different designs in 2 diameters: final results of an international multicenter, randomized, controlled trial. Gastrointest Endosc 2009; 70: 445 - 453

26 Shah RJ, Howell DA, Desilets DJ et al. Multicenter randomized trial of the spiral Z-stent compared with the Wallstent for malignant biliary obstruction. Gastrointest Endosc 2003; 57: 830-836

27 Ballinger $A B$, McHugh M, Catnach SM et al. Symptom relief and quality of life after stenting for malignant bile duct obstruction. Gut 1994; 35: $467-470$

28 Abraham NS, Barkun JS, Barkun AN. Palliation of malignant biliary obstruction: a prospective trial examining impact on quality of life. Gastrointest Endosc 2002; 56: 835-841

29 Luman W, Cull A, Palmer KR. Quality of life in patients stented for malignant biliary obstructions. Eur J Gastroenterol Hepatol 1997; 9: 481 484

30 Weston BR, Ross WA, Wolff RA et al. Rate of bilirubin regression after stenting in malignant biliary obstruction for the initiation of chemotherapy: how soon should we repeat endoscopic retrograde cholangiopancreatography? Cancer 2008; 112: 2417-2423

31 Moss AC, Morris E, Leyden J et al. Malignant distal biliary obstruction: a systematic review and meta-analysis of endoscopic and surgical bypass results. Cancer Treat Rev 2007; 33: $213-221$

32 Artifon ELA, Sakai P, Cunha JEM et al. Surgery or endoscopy for palliation of biliary obstruction due to metastatic pancreatic cancer. Am J Gastroenterol 2006; 101: 2031-2037

33 Moss AC, Morris E, Leyden J et al. Do the benefits of metal stents justify the costs? A systematic review and meta-analysis of trials comparing endoscopic stents for malignant biliary obstruction Eur J Gastroenterol Hepatol 2007; 19: 1119-1124

34 Schmassmann A, von Gunten E, Knuchel J et al. Wallstents versus plastic stents in malignant biliary obstruction: effects of stent patency of the first and second stent on patient compliance and survival. Am J Gastroenterol 1996; 91: 654-659

35 Yeoh KG, Zimmerman MJ, Cunningham JT et al. Comparative costs of metal versus plastic biliary stent strategies for malignant obstructive jaundice by decision analysis. Gastrointest Endosc 1999; 49: 466 - 471

36 Yoon $W$, Ryu J, Yang $K$ et al. A comparison of metal and plastic stents for the relief of jaundice in unresectable malignant biliary obstruction in 
Korea: an emphasis on cost-effectiveness in a country with a low ERCP cost. Gastrointest Endosc 2009; 70: 284-289

37 Speer AG, Cotton PB, MacRae KD. Endoscopic management of malignant biliary obstruction: stents of 10 French gauge are preferable to stents of 8 French gauge. Gastrointest Endosc 1988; 34: 412 - 417

38 Sherman S, Lehman G, Earle $E$ et al. Multicenter randomized trial of 10 French versus 11.5 French plastic stents for malignant bile duct obstruction. Gastrointest Endosc 1996; 43: 396

39 Kadakia SC, Starnes E. Comparison of 10 French gauge stent with 11.5 French gauge stent in patients with biliary tract diseases. Gastrointest Endosc 1992; 38: 454-459

40 Pereira-Lima JC, Jakobs R, Maier M et al. Endoscopic biliary stenting for the palliation of pancreatic cancer: results, survival predictive factors, and comparison of 10 -French with 11.5 -French gauge stents. Am J Gastroenterol 1996; 91: 2179-2184

41 Seitz $U$, Vadeyar $H$, Soehendra N. Prolonged patency with a new-design Teflon biliary prosthesis. Endoscopy 1994; 26: 478 - 482

42 Terruzzi V, Comin U, De Grazia $F$ et al. Prospective randomized trial comparing Tannenbaum Teflon and standard polyethylene stents in distal malignant biliary stenosis. Gastrointest Endosc 2000; 51: 23 - 27

43 Tringali A, Mutignani M, Perri Vet al. A prospective, randomized multicenter trial comparing DoubleLayer and polyethylene stents for malignant distal common bile duct strictures. Endoscopy 2003; 35: $992-$ 997

44 Dua K, Reddy N, Rao V et al. Impact of reducing duodenobiliary reflux on biliary stent patency: an in vitro evaluation and a prospective randomized clinical trial that used a biliary stent with an antireflux valve. Gastrointest Endosc 2007; 65: 819-828

45 Lawrence C, Romagnuolo J, Payne KM et al. Low symptomatic premature stent occlusion of multiple plastic stents for benign biliary strictures: comparing standard and prolonged stent change intervals. Gastrointest Endosc 2010; 72: 558-563

46 Galandi D, Schwarzer G, Bassler D et al. Ursodeoxycholic acid and/or antibiotics for prevention of biliary stent occlusion. Cochrane Database Syst Rev 2002: 03 CD003043

47 Matsuda Y, Shimakura K, Akamatsu T. Factors affecting the patency of stents in malignant biliary obstructive disease: univariate and multivariate analysis. Am J Gastroenterol 1991; 86: 843-849

48 Kullman E, Frozanpor F, Söderlund $C$ et al. Covered versus uncovered self-expandable nitinol stents in the palliative treatment of malignant distal biliary obstruction: results from a randomized, multicenter study. Gastrointest Endosc 2010; 72: 915-923

49 Telford JJ, Carr-Locke DL, Baron TH et al. A randomized trial comparing uncovered and partially covered self-expandable metal stents in the palliation of distal malignant biliary obstruction. Gastrointest Endosc 2010; 72: 907-914

50 Lai EC, Mok FP, Fan ST et al. Preoperative endoscopic drainage for malignant obstructive jaundice. Br J Surg 1994; 81: 1195-1198

51 van der Gaag NA, Rauws EAJ, van Eijck CHJ et al. Preoperative biliary drainage for cancer of the head of the pancreas. N Engl J Med 2010; 362: $129-137$

52 Wang $Q$, Gurusamy KS, Lin $\mathrm{H}$ et al. Preoperative biliary drainage for obstructive jaundice. Cochrane Database Syst Rev 2008: 03 CD005444

53 Motte S, Deviere J, Dumonceau JM et al. Risk factors for septicemia following endoscopic biliary stenting. Gastroenterology 1991; 101: $1374-1381$

54 Chen VK, Arguedas MR, Baron TH. Expandable metal biliary stents before pancreaticoduodenectomy for pancreatic cancer: a Monte-Carlo decision analysis. Clin Gastroenterol Hepatol 2005; 3: 1229-1237

55 Kahaleh M, Brock A, Conaway MR et al. Covered self-expandable metal stents in pancreatic malignancy regardless of resectability: a new concept validated by a decision analysis. Endoscopy 2007; 39: 319-324

56 Mullen JT, Lee JH, Gomez HF et al. Pancreaticoduodenectomy after placement of endobiliary metal stents. J Gastrointest Surg 2005; 9: 1094-1104; discussion 1104-1105

57 Wasan SM, Ross WA, Staerkel GA et al. Use of expandable metallic biliary stents in resectable pancreatic cancer. Am J Gastroenterol 2005; 100: $2056-2061$

58 Siriwardana HPP, Siriwardena AK. Systematic appraisal of the role of metallic endobiliary stents in the treatment of benign bile duct stricture. Ann Surg 2005; 242: 10-19

59 Cannon ME, Carpenter SL, Elta GH et al. EUS compared with CT, magnetic resonance imaging, and angiography and the influence of biliary stenting on staging accuracy of ampullary neoplasms. Gastrointest Endosc 1999; 50: $27-33$
60 Fusaroli P, Manta R, Fedeli $P$ et al. The influence of endoscopic biliary stents on the accuracy of endoscopic ultrasound for pancreatic head cancer staging. Endoscopy 2007; 39: 813-817

61 Kaassis M, Boyer J, Dumas $R$ et al. Plastic or metal stents for malignant stricture of the common bile duct? Results of a randomized prospective study Gastrointest Endosc 2003; 57: 178-182

62 Catalano MF, Geenen JE, Lehman GA et al. "Tannenbaum” Teflon stents versus traditional polyethylene stents for treatment of malignant biliary stricture. Gastrointest Endosc 2002; 55: 354 - 358

63 Prat $F$, Chapat O, Ducot B et al. A randomized trial of endoscopic drainage methods for inoperable malignant strictures of the common bile duct. Gastrointest Endosc 1998; 47: 1 - 7

64 Knyrim K, Wagner HJ, Pausch J et al. A prospective, randomized, controlled trial of metal stents for malignant obstruction of the common bile duct. Endoscopy 1993; 25: 207-212

65 Allison MC, Sandoe JAT, Tighe R et al. Antibiotic prophylaxis in gastrointestinal endoscopy. Gut 2009; 58: 869-880

66 Dumonceau J-M, Deviere J, Cremer M. A new method of achieving deep cannulation of the common bile duct during endoscopic retrograde cholangiopancreatography. Endoscopy 1998; 30: S80

67 Dumonceau J-M, Andriulli A, Deviere J et al. European Society of Gastrointestinal Endoscopy (ESGE) Guideline: prophylaxis of post-ERCP pancreatitis. Endoscopy 2010; 42: 503-515

68 Dumonceau J-M, Rigaux J, Kahaleh $M$ et al. Prophylaxis of post-ERCP pancreatitis: a practice survey. Gastrointest Endosc 2010; 71: $934-$ 939

69 Cotton P, Garrow D, Gallagher J et al. Risk factors for complications after ERCP: a multivariate analysis of 11,497 procedures over 12 years. Gastrointest Endosc 2009; 70: 80 - 88

70 Boustière C, Veitch AM, Vanbiervliet $G$ et al. Endoscopy and antiplatelet agents. ESGE Guideline. Endoscopy 2011; 43: 445-61

71 Van Os EC, Kamath PS, Gostout CJ et al. Gastroenterological procedures among patients with disorders of hemostasis: evaluation and management recommendations. Gastrointest Endosc 1999; 50: 536- 543

72 Veitch AM, Baglin TP, Gershlick AH et al. Guidelines for the management of anticoagulant and antiplatelet therapy in patients undergoing endoscopic procedures. Gut 2008; 57: 1322-1329

73 Arhan M, Odemiş B, ParlakE et al. Migration of biliary plastic stents: experience of a tertiary center. Surg Endosc 2009; 23: 769-775

74 Ho H, Mahajan A, Gosain S et al. Management of complications associated with partially covered biliary metal stents. Dig Dis Sci 2010; 55: $516-522$

75 Traina M, Tarantino I, Barresi $L$ et al. Efficacy and safety of fully covered self-expandable metallic stents in biliary complications after liver transplantation: A preliminary study. Liver Transpl 2009; 15: 1493 1498

76 Familiari P, Bulajic M, Mutignani $M$ et al. Endoscopic removal of malfunctioning biliary self-expandable metallic stents. Gastrointest Endosc 2005; 62: $903-910$

77 Johanson JF, Schmalz MJ, Geenen JE. Incidence and risk factors for biliary and pancreatic stent migration. Gastrointest Endosc 1992; 38: 341 346

78 Bueno JT, Gerdes H, Kurtz RC. Endoscopic management of occluded biliary Wallstents: a cancer center experience. Gastrointest Endosc 2003; 58: $879-884$

79 Rogart JN, Boghos A, Rossi F et al. Analysis of endoscopic management of occluded metal biliary stents at a single tertiary care center. Gastrointest Endosc 2008; 68: 676-682

80 Tham TC, Carr-Locke DL, Vandervoort J et al. Management of occluded biliary Wallstents. Gut 1998; 42: 703-707

81 Cho JH, Jeon TJ, ParkJY et al. Comparison of outcomes among secondary covered metallic, uncovered metallic, and plastic biliary stents in treating occluded primary metallic stents in malignant distal biliary obstruction. Surg Endosc 2011; 25: 475-482

82 Togawa $\mathrm{O}$, Kawabe T, Isayama $\mathrm{H}$ et al. Management of occluded uncovered metallic stents in patients with malignant distal biliary obstructions using covered metallic stents. J Clin Gastroenterol 2008; 42: $546-549$

83 Fumex F, Coumaros D, Napoleon B et al. Similar performance but higher cholecystitis rate with covered biliary stents: results from a prospective multicenter evaluation. Endoscopy 2006; 38: 787-792

84 Ornellas LC, Stefanidis G, Chuttani R et al. Covered Wallstents for palliation of malignant biliary obstruction: primary stent placement versus reintervention. Gastrointest Endosc 2009; 70: 676-683 
85 Suk KT, Kim HS, Kim JW et al. Risk factors for cholecystitis after metal stent placement in malignant biliary obstruction. Gastrointest Endosc 2006; 64: 522 - 529

86 Yoon WJ, Lee JK, Lee KH et al. A comparison of covered and uncovered Wallstents for the management of distal malignant biliary obstruction. Gastrointest Endosc 2006; 63: 996 - 1000

87 Isayama $\mathrm{H}$, Kawabe T, Nakai $Y$ et al. Cholecystitis after metallic stent placement in patients with malignant distal biliary obstruction. Clin Gastroenterol Hepatol 2006; 4: 1148 - 1153

88 Gosain S, Bonatti H, Smith $L$ et al. Gallbladder stent placement for prevention of cholecystitis in patients receiving covered metal stent for malignant obstructive jaundice: a feasibility study. Dig Dis Sci 2010; 55: $2406-2411$

89 Akamatsu N, Sugawara Y, Osada $\mathrm{H}$ et al. Diagnostic accuracy of multidetector-row computed tomography for hilar cholangiocarcinoma. J Gastroenterol Hepatol 2010; 25: 731 -737

90 Park HS, Lee JM, Choi J-Y et al. Preoperative evaluation of bile duct cancer: MRI combined with MR cholangiopancreatography versus MDCT with direct cholangiography. AJR Am J Roentgenol 2008; 190: 396 405

91 Choi J-Y, Kim M-J, Lee JM et al. Hilar cholangiocarcinoma: role of preoperative imaging with sonography, MDCT, MRI, and direct cholangiography. AJR Am J Roentgenol 2008; 191: 1448 - 1457

92 Masselli G, Manfredi R, Vecchioli A et al. MR imaging and MR cholangiopancreatography in the preoperative evaluation of hilar cholangiocarcinoma: correlation with surgical and pathologic findings. Eur Radiol 2008; $18: 2213-2221$

93 Fritscher-Ravens A, Broering DC, Knoefel WT et al. EUS-guided fine-needle aspiration of suspected hilar cholangiocarcinoma in potentially operable patients with negative brush cytology. Am J Gastroenterol 2004; 99: 45-51

94 Larghi A, Lecca PG, Ardito F et al. Evaluation of hilar biliary strictures by using a newly developed forward-viewing therapeutic echoendoscope: preliminary results of an ongoing experience. Gastrointest Endosc 2009; 69: 356-360

95 Lee SH, Park JK, Yoon WJ et al. Optimal biliary drainage for inoperable Klatskin's tumor based on Bismuth type. World J Gastroenterol 2007; 13: $3948-3955$

96 Saluja SS, Gulati M, Garg PK et al. Endoscopic or percutaneous biliary drainage for gallbladder cancer: a randomized trial and quality of life assessment. Clin Gastroenterol Hepatol 2008; 6: 944-950 e943

97 Paik WH, Park YS, Hwang J-H et al. Palliative treatment with self-expandable metallic stents in patients with advanced type III or IV hilar cholangiocarcinoma: a percutaneous versus endoscopic approach. Gastrointest Endosc 2009; 69: 55-62

98 Chang WH, Kortan P, Haber GB. Outcome in patients with bifurcation tumors who undergo unilateral versus bilateral hepatic duct drainage. Gastrointest Endosc 1998; 47: 354-362

99 Geller A. Klatskin tumor - palliative therapy: the jury is still out or may be not yet in. Gastrointest Endosc 2009; 69: 63-65

100 Cotton $P B$. Income and outcome metrics for the objective evaluation of ERCP and alternative methods. Gastrointest Endosc 2002; 56: $283-290$

101 Vogl TJ, Schwarz WO, Heller M et al. Staging of Klatskin tumours (hilar cholangiocarcinomas): comparison of MR cholangiography, MR imaging, and endoscopic retrograde cholangiography. Eur Radiol 2006: 16: $2317-2325$

102 Cha JH, Han JK, Kim TK et al. Preoperative evaluation of Klatskin tumor: accuracy of spiral CT in determining vascular invasion as a sign of unresectability. Abdom Imaging 2000; 25: 500-507

103 Muggli D, Müller MA, Karlo $C$ et al. A simple method to approximate liver size on cross-sectional images using living liver models. Clin Radiol 2009; 64: $682-689$

104 Hintze RE, Abou-Rebyeh $H$, Adler A et al. Magnetic resonance cholangiopancreatography-guided unilateral endoscopic stent placement for Klatskin tumors. Gastrointest Endosc 2001; 53: 40-46

105 Vienne A, Hobeika E, Gouya $H$ et al. Prediction of drainage effectiveness during endoscopic stenting of malignant hilar strictures: the role of liver volume assessment. Gastrointest Endosc 2010; 72: $728-735$

106 Deviere J, Baize M, de Toeuf J et al. Long-term follow-up of patients with hilar malignant stricture treated by endoscopic internal biliary drainage. Gastrointest Endosc 1988; 34: 95 - 101
107 Polydorou AA, Chisholm EM, Romanos AA et al. A comparison of right versus left hepatic duct endoprosthesis insertion in malignant hilar biliary obstruction. Endoscopy 1989; 21: $266-271$

108 Freeman ML, Overby C. Selective MRCP and CT-targeted drainage of malignant hilar biliary obstruction with self-expanding metallic stents. Gastrointest Endosc 2003; 58: 41-49

109 Singh V, Singh G, Verma GR et al. Contrast-free unilateral endoscopic palliation in malignant hilar biliary obstruction: new method. J Gastroenterol Hepatol 2004; 19: 589-592

110 Inal M, Akgül E, Aksungur E et al. Percutaneous placement of biliary metallic stents in patients with malignant hilar obstruction: unilobar versus bilobar drainage. J Vasc Interv Radiol 2003; 14: 1409-1416

111 Naitoh I, Ohara H, Nakazawa T et al. Unilateral versus bilateral endoscopic metal stenting for malignant hilar biliary obstruction.J Gastroenterol Hepatol 2009; 24: $552-557$

112 Banerjee S, Shen B, Baron TH et al. Antibiotic prophylaxis for GI endoscopy. Gastrointest Endosc 2008; 67: 791 - 798

113 Wagner HJ, Knyrim K, Vakil N et al. Plastic endoprostheses versus metal stents in the palliative treatment of malignant hilar biliary obstruction. A prospective and randomized trial. Endoscopy 1993; 25: 213 218

114 Perdue DG, Freeman ML, Disario JA et al. Plastic versus self-expanding metallic stents for malignant hilar biliary obstruction: a prospective multicenter observational cohort study. J Clin Gastroenterol 2008; 42: 1040 - 1046

115 Nguyen-Tang T, Dumonceau J-M. A new method to facilitate bilateral hepatic duct drainage: simultaneous insertion of two thin 6-Fr selfexpandable metal stents. Endoscopy 2011; 43: (Suppl.02) E24-E25

116 Saleem A, Baron TH, Gostout CJ. Large-diameter therapeutic channel duodenoscope to facilitate simultaneous deployment of side-by-side self-expandable metal stents in hilar cholangiocarcinoma. Gastrointest Endosc 2010; 72: 628-631

117 Ortner MEJ, Caca K, Berr F et al. Successful photodynamic therapy for nonresectable cholangiocarcinoma: a randomized prospective study. Gastroenterology 2003; 125: 1355-1363

118 Zoepf T, Jakobs R, Arnold JC et al. Palliation of nonresectable bile duct cancer: improved survival after photodynamic therapy. Am J Gastroenterol 2005; 100: 2426-2430

119 Gerhardt T, Rings D, Höblinger A et al. Combination of bilateral metal stenting and trans-stent photodynamic therapy for palliative treatment of hilar cholangiocarcinoma. Z Gastroenterol 2010; 48: 28 - 32

120 Wang $L-W$, Li L-B, Li Z-S et al. Self-expandable metal stents and transstent light delivery: are metal stents and photodynamic therapy compatible? Lasers Surg Med 2008; 40: 651 -659

121 Dumonceau JM, Devière J. Self-expandable metal stents. Baillieres Best Pract Res Clin Gastroenterol 1999; 13: 109-130

122 van Boeckel PGA, Vleggaar FP, Siersema PD. Plastic or metal stents for benign extrahepatic biliary strictures: a systematic review. BMC Gastroenterology 2009; 9: 96

123 Catalano MF, Linder JD, George $S$ et al. Treatment of symptomatic distal common bile duct stenosis secondary to chronic pancreatitis: comparison of single vs. multiple simultaneous stents. Gastrointest Endosc 2004; 60: 945 -952

124 Draganov P, Hoffman B, Marsh Wet al. Long-term outcome in patients with benign biliary strictures treated endoscopically with multiple stents. Gastrointest Endosc 2002; 55: 680-686

125 Pozsár J, Sahin P, László $F$ et al. Medium-term results of endoscopic treatment of common bile duct strictures in chronic calcifying pancreatitis with increasing numbers of stents. J Clin Gastroenterol 2004; 38: $118-123$

126 Nguyen-Tang T, Dumonceau J-M. Endoscopic treatment in chronic pancreatitis, timing, duration and type of intervention. Best Pract Res Clin Gastroenterol 2010; 24: 281-298

127 Kuzela L, Oltman M, Sutka J et al. Prospective follow-up of patients with bile duct strictures secondary to laparoscopic cholecystectomy, treated endoscopically with multiple stents. Hepato-Gastroenterology 2005; 52: $1357-1361$

128 Morelli G, Fazel A, Judah J et al. Rapid-sequence endoscopic management of posttransplant anastomotic biliary strictures. Gastrointest Endosc 2008; 67: 879-885

129 Costamagna G, Tringali A, Mutignani $M$ et al. Endotherapy of postoperative biliary strictures with multiple stents: results after more than 10 years of follow-up. Gastrointest Endosc 2010; 72: 551 - 557

130 Tabibian JH, Asham EH, Han S et al. Endoscopic treatment of postorthotopic liver transplantation anastomotic biliary strictures with 
maximal stent therapy (with video). Gastrointest Endosc 2010; 71: 505-512

131 Behm B, Brock A, Clarke BW et al. Partially covered self-expandable metallic stents for benign biliary strictures due to chronic pancreatitis. Endoscopy 2009; 41: 547-551

132 Chaput U, Scatton O, Bichard P et al. Temporary placement of partially covered self-expandable metal stents for anastomotic biliary strictures after liver transplantation: a prospective, multicenter study. Gastrointest Endosc 2010; 72: 1167-1174

133 Kahaleh M, Behm B, Clarke BW et al. Temporary placement of covered self-expandable metal stents in benign biliary strictures: a new paradigm? (with video) Gastrointest Endosc 2008; 67: 446 - 454

134 Sauer B, Regan K, Srinivasan I et al. Placement of covered self-expandable metal stents (CSEMS) in benign biliary strictures (BBS): eight years of experience. Gastrointest Endosc 2010; 71: AB110-AB111

135 Kiehne K, Fölsch UR, Nitsche R. High complication rate of bile duct stents in patients with chronic alcoholic pancreatitis due to noncompliance. Endoscopy 2000; 32: $377-380$

136 Mahajan A, Ho H, Sauer B et al. Temporary placement of fully covered self-expandable metal stents in benign biliary strictures: midterm evaluation (with video). Gastrointest Endosc 2009; 70: 303 - 309

137 Cahen DL, Rauws EA, Gouma DJ et al. Removable fully covered self-expandable metal stents in the treatment of common bile duct strictures due to chronic pancreatitis: a case series. Endoscopy 2008; 40: $697-700$

138 Bourke MJ, Elfant AB, Alhalel R et al. Sphincterotomy-associated biliary strictures: features and endoscopic management. Gastrointest Endosc 2000; 52: $494-499$

139 Costamagna G, Pandolfi M, Mutignani $M$ et al. Long-term results of endoscopic management of postoperative bile duct strictures with increasing numbers of stents. Gastrointest Endosc 2001; 54: 162 - 168

140 Sugiyama M, Atomi $Y$. Risk factors predictive of late complications after endoscopic sphincterotomy for bile duct stones: long-term (more than 10 years) follow-up study. Am J Gastroenterol 2002; 97: $2763-2767$

141 Sandha GS, Bourke MJ, Haber GB et al. Endoscopic therapy for bile leak based on a new classification: results in 207 patients. Gastrointest Endosc 2004; 60: 567-574

142 Aksoz K, Unsal B, Yoruk G et al. Endoscopic sphincterotomy alone in the management of low-grade biliary leaks due to cholecystectomy. Dig Endosc 2009; 21: $158-161$
143 Llach J, Bordas JM, Elizalde JI et al. Sphincterotomy in the treatment of biliary leakage. Hepato-Gastroenterology 2002; 49: 1496-1498

144 Marks JM, Ponsky JL, Shillingstad RB et al. Biliary stenting is more effective than sphincterotomy in the resolution of biliary leaks. Surg Endosc 1998; 12: $327-330$

145 Katsinelos P, Kountouras J, Paroutoglou G et al. A comparative study of 10 -Fr vs. 7-Fr straight plastic stents in the treatment of postcholecystectomy bile leak. Surg Endosc 2008; 22: 101 - 106

146 Coté GA, Ansstas M, Shah $S$ et al. Findings at endoscopic retrograde cholangiopancreatography after endoscopic treatment of postcholecystectomy bile leaks. Surg Endosc 2010; 24: 1752-1756

147 Bergman JJ, Rauws EA, Tijssen JG et al. Biliary endoprostheses in elderly patients with endoscopically irretrievable common bile duct stones: report on 117 patients. Gastrointest Endosc 1995; 42: 195 201

148 Chan AC, Ng EK, Chung SC et al. Common bile duct stones become smaller after endoscopic biliary stenting. Endoscopy 1998; 30: $356-$ 359

149 Han J, Moon JH, Koo HC et al. Effect of biliary stenting combined with ursodeoxycholic acid and terpene treatment on retained common bile duct stones in elderly patients: a multicenter study. Am J Gastroenterol 2009; 104: 2418-2421

150 Pisello F, Geraci G, Li Volsi F et al. Permanent stenting in "unextractable" common bile duct stones in high risk patients. A prospective randomized study comparing two different stents. Langenbecks Arch Surg 2008; 393: 857-863

151 Jain SK, Stein R, Bhuva M et al. Pigtail stents: an alternative in the treatment of difficult bile duct stones. Gastrointest Endosc 2000; 52: 490-493

152 Horiuchi A, Nakayama Y, Kajiyama $M$ et al. Biliary stenting in the management of large or multiple common bile duct stones. Gastrointest Endosc 2010; 71: 1200-1203 e1202

153 Katsinelos P, Kountouras J, Paroutoglou G et al. Combination of endoprostheses and oral ursodeoxycholic acid or placebo in the treatment of difficult to extract common bile duct stones. Dig Liver Dis 2008; 40: $453-459$

154 Somerville KW, Ellis WR, Whitten BH et al. Stones in the common bile duct: experience with medical dissolution therapy. Postgrad Med J 1985; 61: $313-316$

Appendix 1 2, and 3 are available online:

online content viewable at:

www.thieme-connect.de/ejournals/abstract/endoscopy/

doi/10.1055/s-0031-1291633 
Appendix e1 Chapter structure, task forces, and key questions.

\section{Chapter/Topic complex}

1 Stent insertion

- Should biliary sphincterotomy be performed?

- What should be done in the case of failed stent insertion?

2 Short-term (1-month) efficacy of stents for biliary drainage

- How do plastic stents compare with SEMSs?

- How do models of plastic stents compare?

- How do models of SEMSs compare (including covered vs. uncovered)?

3 Long-term efficacy of stents for palliation of malignant CBD obstruction

- How do plastic stents compare with SEMSs?

- How do models of plastic stents compare?

- Can medication prolong the patency of plastic stents?

- How do models of SEMS compare (including covered vs uncovered)?

- Does the type of stent used influence survival length?

4 Indications for stenting and stent selection in patients with a potentially resectable CBD obstruction?

- - In which cases should stenting be performed?

- - Which stent should be used?

5 Complications of biliary stenting

- What are the early complications of stent insertion?

- How can these be prevented?

- What are the late complications of biliary stenting?

- Are some late complications more frequent with some stent models (excluding timing of stent dysfunction, will be treated in topics above)?

- What are the mechanisms of stent dysfunction, depending on stent model?

- How should late complications (including stent dysfunction) be treated?

\section{Particular cases}

\section{1 Hilar strictures}

- Might biliary stenting affect the assessment of tumor resectability?

- When should biliary drainage be performed by endoscopic, percutaneous, or combined routes?

- Should drainage of hilar strictures be performed in tertiary centers only?

- Are some pre-stenting imaging procedures particularly useful, and what information should be looked for?

- Should drainage be unilateral or bilateral for bilateral strictures?

- Can recommendations be made about the type of stent (plastic or metal)?

- Do SEMSs impede photodynamic therapy?

- How to proceed in the case of stent dysfunction?

\subsection{Benign biliary strictures}

- What are the causes of benign biliary strictures?

- Which biliary strictures respond best in the long term to stenting?

- Should plastic or metal stents be used for benign biliary structures?

- With plastic stents, should a strategy be preferred?

- With covered SEMSs, should a strategy be preferred?

\subsection{Biliary leaks}

- Should stenting, sphincterotomy, or both be performed?

- Which type of stent should be used?

- For how long should stenting be performed?

- Which associated measures should be employed(drain bihoma...)?

\subsection{Biliary stones}

- What is the frequency of failure of stone extraction?

- What are the alternatives to biliary stenting in the case of failed stone extraction?

- Should biliary stenting be a preferred alternative?

- Should biliary stenting be maintained for the long term?

- Should a drug be prescribed to assist stone fragmentation?
Task forces (spokespersons in bold)

Jean-Marc Dumonceau

Andrea Tringali

Jean-Marc Dumonceau

Andrea Tringali

\section{Jean-Marc Dumonceau}

Daniel Blero, Jacques Devière

\section{Daniel Blero}

Jacques Devière

\section{Daniel Blero}

Jean-Marc Dumonceau

\section{Andrea Tringali}

Guido Costamagna, Jacques Devière,

Jean-Marc Dumonceau

Jean-Marc Dumonceau

Guido Costamagna

\section{Daniel Blero}

Jacques Devière

\section{Daniel Blero}

Jacques Devière, Andrea Tringali

SEMS, self-expanding metal stent; CBD, common bile duct. 


\begin{tabular}{|c|c|c|}
\hline Topic complex & $\begin{array}{l}\text { Number of initial references according } \\
\text { to the predefined key questions }\end{array}$ & $\begin{array}{l}\text { Number of relevant references for } \\
\text { the guideline after evaluation }\end{array}$ \\
\hline Task force 1 & 195 & 15 \\
\hline Task force 2 & 265 & 13 \\
\hline Task force 3 & 265 & 34 \\
\hline Task force 4 & 25 & 9 \\
\hline Task force 5 & 366 & 28 \\
\hline Task force 6.1. & 51 & 34 \\
\hline Task force 6.2 . & 171 & 17 \\
\hline Task force 6.3. & 205 & 7 \\
\hline Task force 6.4 . & 289 & 9 \\
\hline
\end{tabular}

Appendix e2 Evidence table.

\begin{tabular}{|llccl|}
\hline Complication & $\begin{array}{l}\text { Plastic stent } \\
(\mathbf{n = 8 2 5 )}\end{array}$ & $\begin{array}{l}\text { Uncovered SEMS } \\
(\mathbf{n = 7 2 4 )}\end{array}$ & $\begin{array}{l}\text { Partly covered SEMS } \\
(\mathbf{n = 1 1 0 7 )}\end{array}$ & $\begin{array}{l}\text { Fully covered SEMS } \\
(\mathbf{n = 8 1 )}\end{array}$ \\
\hline Cholecystitis & $<0.5 \%$ & $1 \%$ & $4 \%$ & Not applicable $^{1}$ \\
\hline Stent dysfunction & $21 \%$ & $27 \%$ & $20 \%$ & $23 \%$ \\
\hline - Migration & $6 \%$ & $1 \%$ & $7 \%$ & $21 \%$ \\
\hline - Clogging & $34 \%$ & $4 \%$ & $6 \%$ & $7 \%$ \\
\hline - Tumor ingrowth & Not applicable & $18 \%$ & $7 \%$ & Not applicable \\
\hline - Tissue overgrowth & Not applicable & $7 \%$ & $5 \%$ & Not applicable \\
\hline
\end{tabular}

Appendix e3

Table A Summary of stentrelated complications.

SEMS, self-expandable metal stent.

Complications were recorded when specifically reported in prospective studies. The lists of specific studies used to compile this table are available online.

${ }^{1}$ Most patients had biliary strictures complicating liver transplantation and no gallbladder in situ or a plastic stent inserted into the gallbladder

when the cystic duct was covered by the SEMS) 157.

${ }^{2}$ Some patients concomitantly had different causes of stent dysfunction. 
Appendix e3

Table B Plastic stents.

\begin{tabular}{|c|c|c|c|c|c|c|}
\hline $\begin{array}{l}\text { Study type } \\
\text { Publication details }\end{array}$ & Type of stent & Indication & Cholecystitis & Dysfunction & Stent migration & Clogging \\
\hline \multicolumn{7}{|l|}{ Randomized controlled trials } \\
\hline $\begin{array}{l}\text { Shepherd et al. } \\
\text { BJS (1988); } 75: 1166-1168\end{array}$ & $\mathrm{PE}$ & M & Not reported & $91 \%(21 / 25)$ & Not reported & Not reported \\
\hline $\begin{array}{l}\text { Andersen et al. } \\
\text { Gut (1989); 30: } 1132-1135\end{array}$ & Not reported & M & $4 \%(1 / 25)$ & $28 \%(7 / 25)$ & Not reported & Not reported \\
\hline $\begin{array}{l}\text { Knyrim et al. } \\
\text { Endoscopy (1993); 25: 207-212 }\end{array}$ & PE & M & Not reported & $43 \%(12 / 28)$ & $7 \%(2 / 28)$ & $36 \%(10 / 28)$ \\
\hline $\begin{array}{l}\text { Smith et al. } \\
\text { Lancet (1994); 344: } 1655-1660\end{array}$ & PE & M & Not reported & $36 \%(36 / 100)$ & Not reported & Not reported \\
\hline $\begin{array}{l}\text { Costamagna et al. } \\
\text { Gastrointest Endosc (2000); 51: 8-11 }\end{array}$ & $\mathrm{PUH} / \mathrm{PE}$ & M & Not reported & $42 \%(25 / 62)$ & Not reported & $42 \%(25 / 62)$ \\
\hline $\begin{array}{l}\text { Davids et al. } \\
\text { Lancet (1992); 340: } 1488-1492\end{array}$ & PE & M & Not reported & $54 \%(30 / 56)$ & $1.8 \%(1 / 56)$ Distal & $52 \%(29 / 56)$ \\
\hline $\begin{array}{l}\text { Kaassis et al. } \\
\text { Gastrointest Endosc (2003); 57: } \\
78-82\end{array}$ & TT & M & Not reported & $37 \%(22 / 59)$ & Not reported & $37 \%(22 / 59)$ \\
\hline $\begin{array}{l}\text { Katsinelos et al. } \\
\text { Surg Endosc (2006); 20:1587 - } 1593\end{array}$ & TT & M & Not reported & $63 \%(15 / 24)$ & Not reported & $63 \%(15 / 24)$ \\
\hline $\begin{array}{l}\text { Soderlund et al. } \\
\text { Gastrointest Endosc (2006); 63: } \\
986-995\end{array}$ & PE & M & Not reported & $43 \%(22 / 51)$ & $4 \%(2 / 51)$ & $39 \%(20 / 51)$ \\
\hline Tringali et al. & DLS & M & Not reported & $43 \%(26 / 60)$ & $10 \%(6 / 60)$ Distal & $33 \%(20 / 60)$ \\
\hline Endoscopy (2003); 35: 992 - 997 & PE & M & Not reported & $63 \%(38 / 60)$ & $8 \%(5 / 60)$ Distal & $55 \%(33 / 60)$ \\
\hline Dua et al. & AR-TT & M & Not reported & $50 \%(12 / 24)$ & $8 \%(2 / 24) 2$ distal & Not reported \\
\hline $\begin{array}{l}\text { Gastrointest Endosc (2007); 65: } \\
819-826\end{array}$ & TT & M & Not reported & $66 \%(16 / 24)$ & $\begin{array}{l}8 \%(2 / 24) 1 \text { proxi- } \\
\text { mal }+1 \text { distal }\end{array}$ & Not reported \\
\hline \multicolumn{7}{|l|}{ Prospective studies } \\
\hline $\begin{array}{l}\text { Tocchi et al. } \\
\text { Arch Surg (2000); 135: 153-157 }\end{array}$ & $\mathrm{PE}$ & B & Not reported & $25 \%(5 / 20)$ & $5 \%(1 / 20)$ Distal & $20 \%(4 / 20)$ \\
\hline $\begin{array}{l}\text { Kahl et al. } \\
\text { Am J Gastroenterol (2003); } 98 \text { : } \\
\text { 2448-2453 }\end{array}$ & $\mathrm{PE}$ & B & Not reported & $34 \%(21 / 61)$ & $8 \%(8 / 61)$ & $16.4 \%(10 / 61)$ \\
\hline $\begin{array}{l}\text { Kuzela et al. } \\
\text { Hepatogastroenterology (2005); 52: } \\
\text { 1357-1361 }\end{array}$ & $\mathrm{PE}$ & B & Not reported & 0 & 0 & 0 \\
\hline $\begin{array}{l}\text { Pozsar et al. Gastrointest Endosc } \\
\text { (2005); 62: 85-91 }\end{array}$ & Teflon WC & B & Not reported & $37.7 \%(20 / 54)$ & $\begin{array}{l}5 / 54(9.2 \%) \text { Overall } \\
4 / 54(7.4 \%) \\
1 / 54(1.9 \%) \mid\end{array}$ & $15 / 54(27.7 \%)$ \\
\hline $\begin{array}{l}\text { Graziadei et al. } \\
\text { Liver Transpl (2006); 12: 718-725 }\end{array}$ & $\mathrm{PE}$ & B & Not reported & $0 / 64$ & $0 / 64$ & $0 / 64$ \\
\hline $\begin{array}{l}\text { Holt et al. } \\
\text { Transplantation (2007); 84: 857-863 }\end{array}$ & $\mathrm{PE}$ & B & Not reported & Not reported & $1.9 \%(1 / 53)$ & Not reported \\
\hline $\begin{array}{l}\text { Perdue et al. } \\
\text { J Clin Gastroenterol (2008); } 42 \text { : } \\
1040-1046\end{array}$ & Not reported & $\mathrm{M}(\mathrm{HT})$ & Not reported & $11 / 28(39 \%)$ & $7.1 \%(2 / 28)$ & $6 / 28(21.4 \%)$ \\
\hline Total & & & & $339 / 825=41 \%$ & $37 / 583=6.3 \%$ & $\begin{array}{l}209 / 627 \\
(33.33 \%)\end{array}$ \\
\hline
\end{tabular}




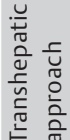

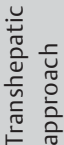

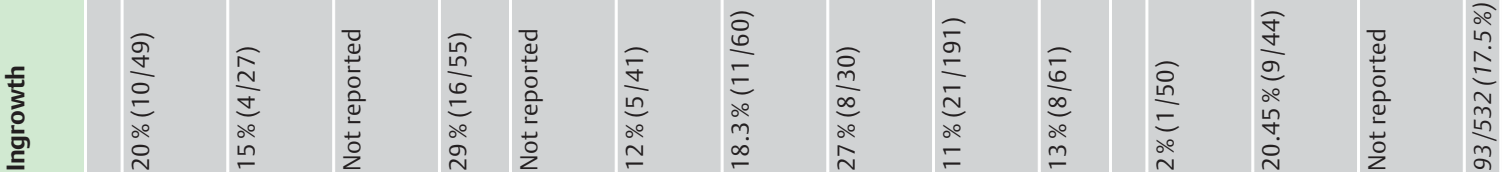

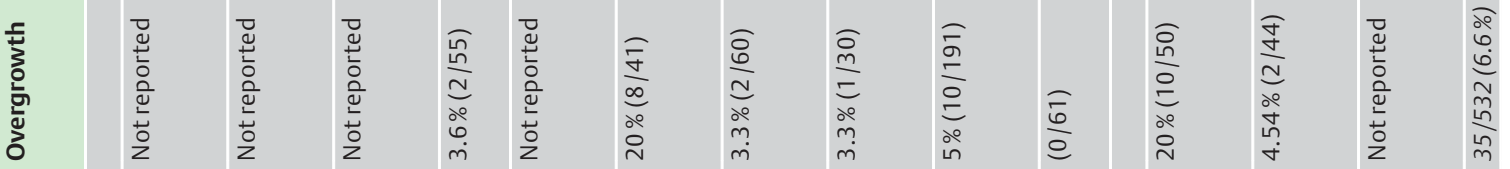

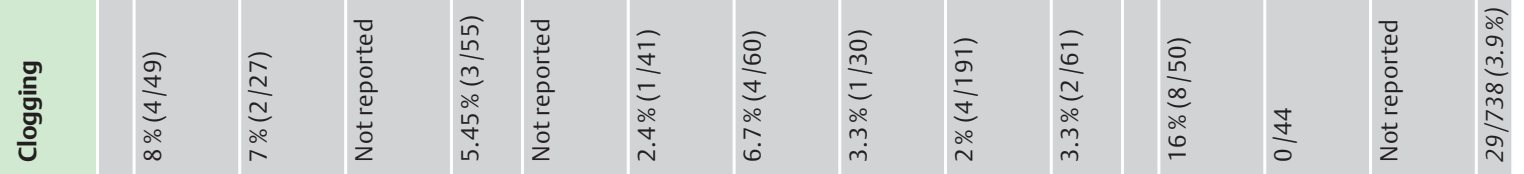

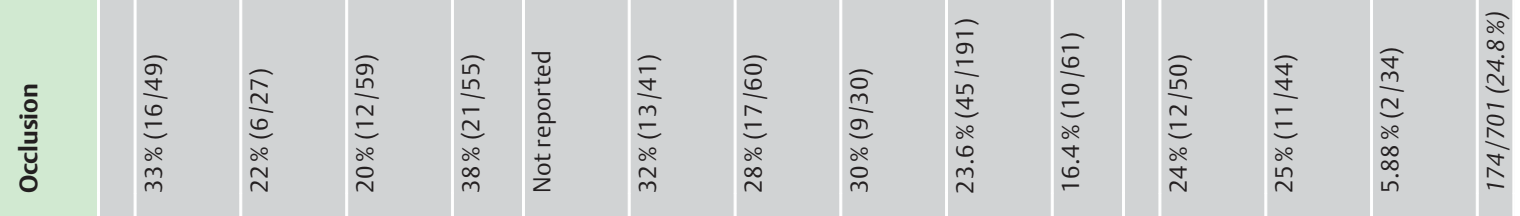

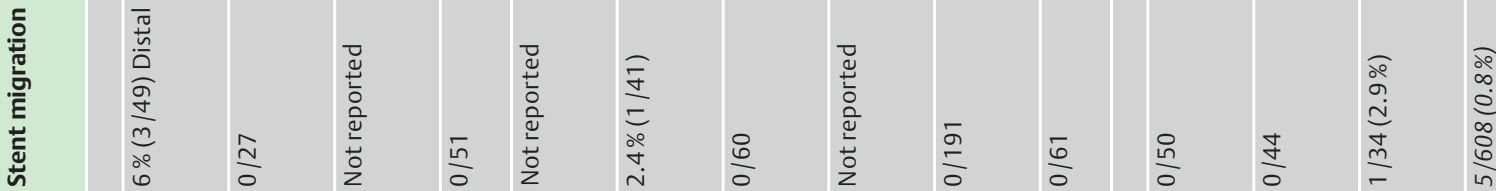

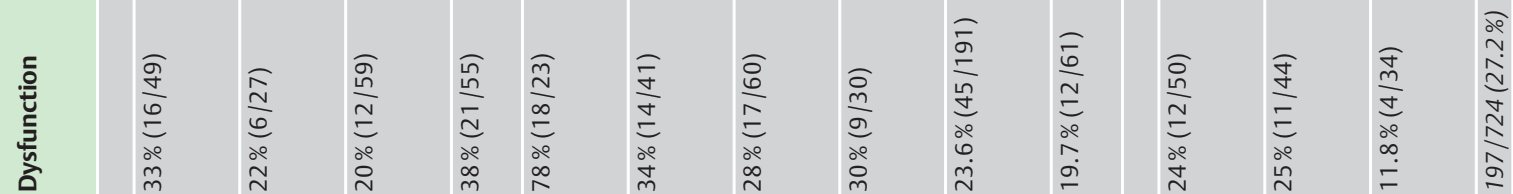

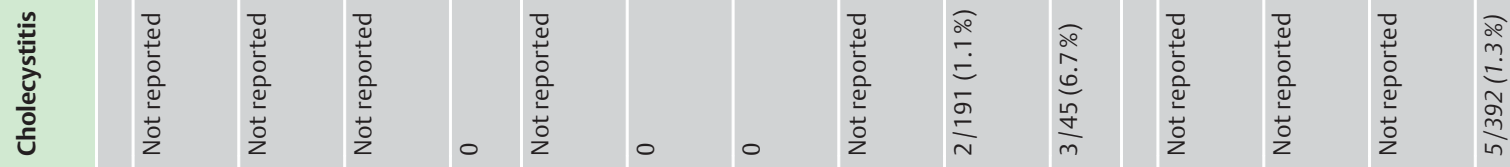

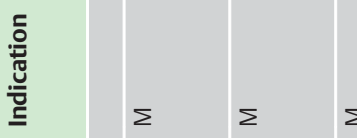

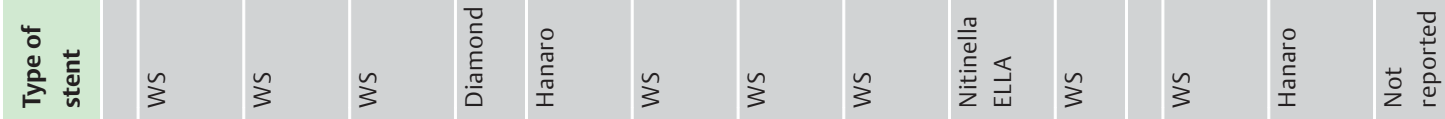

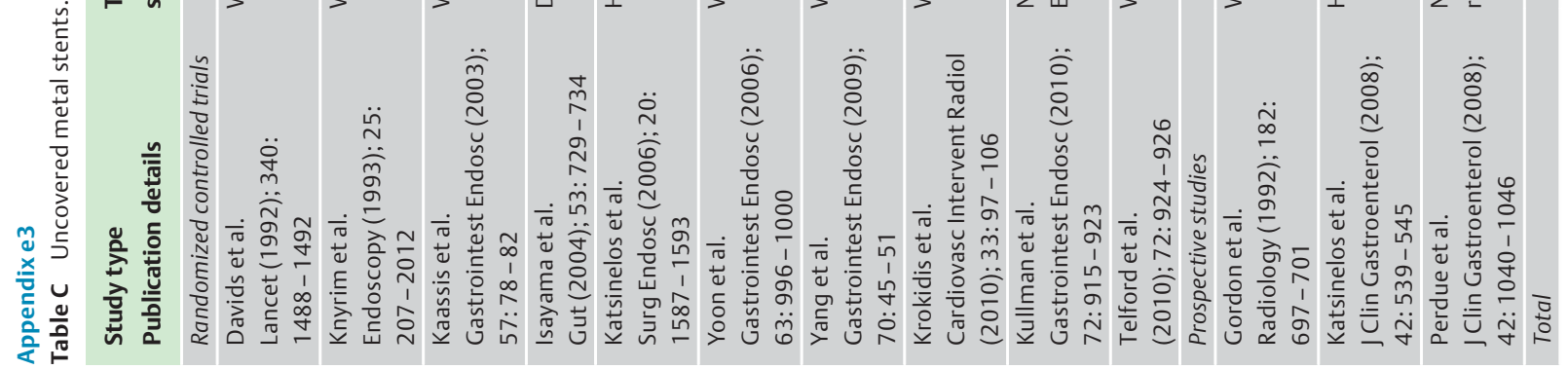



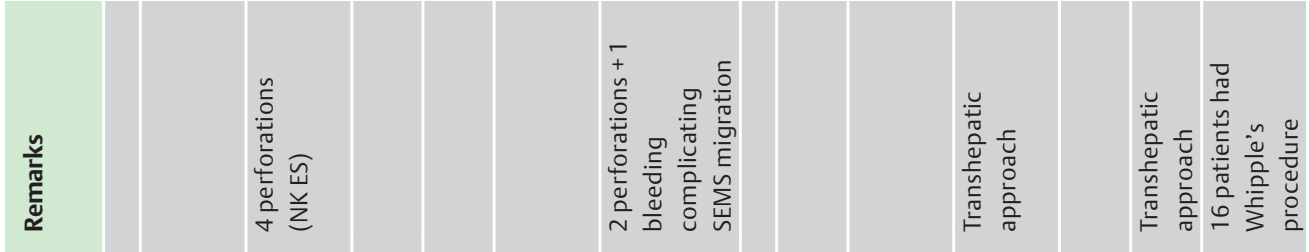

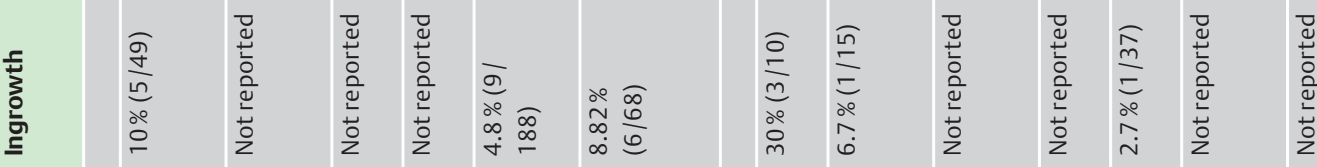

$\begin{array}{ccc}\hat{0} & 0 \\ \infty & \infty \\ & \infty \\ & 0\end{array}$

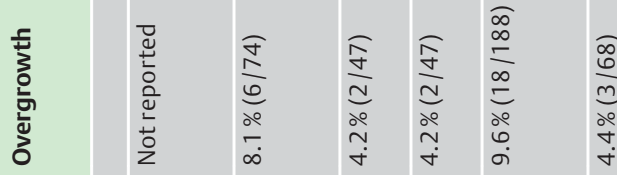

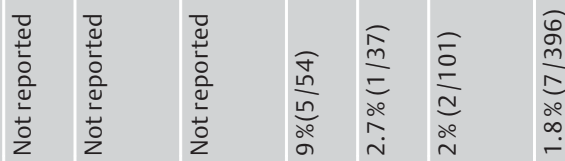

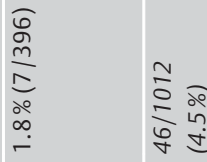

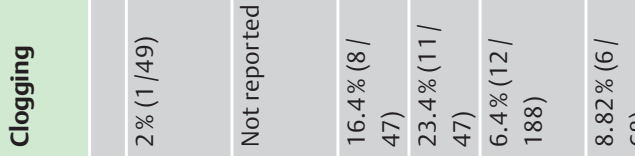

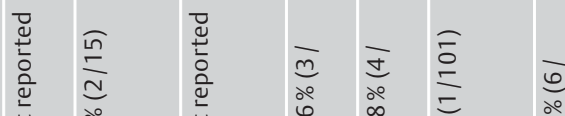

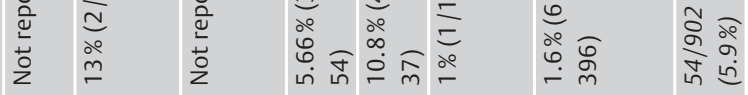

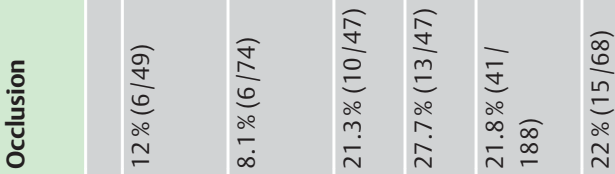

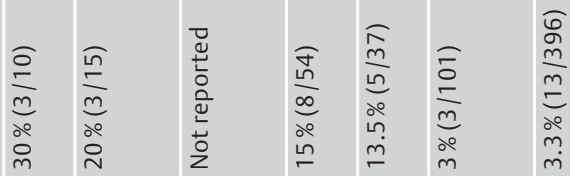

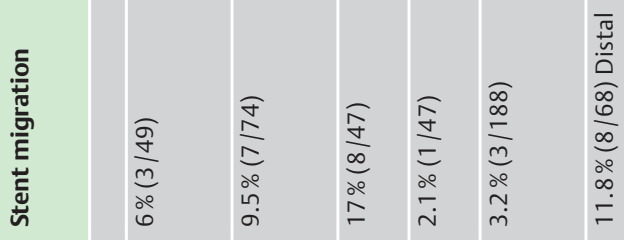

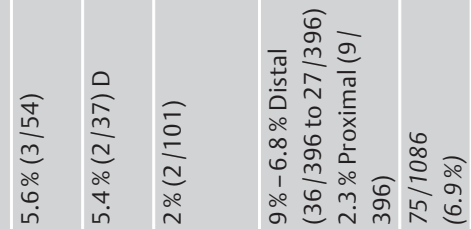

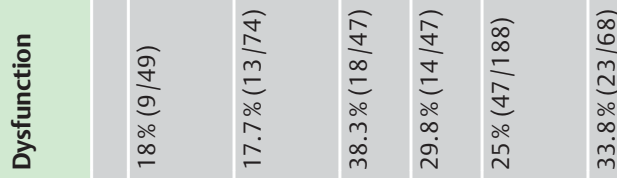

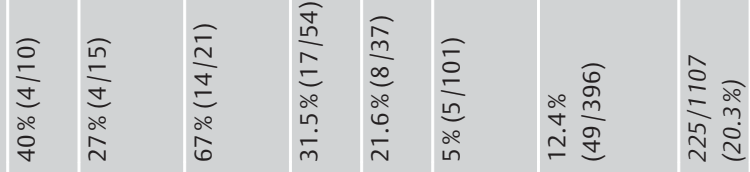

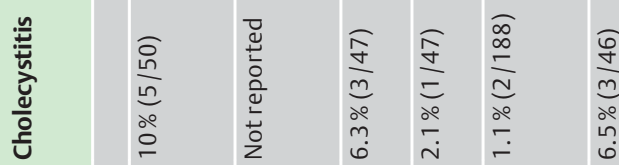

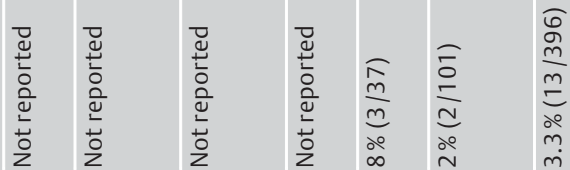

aิ ๖ำ

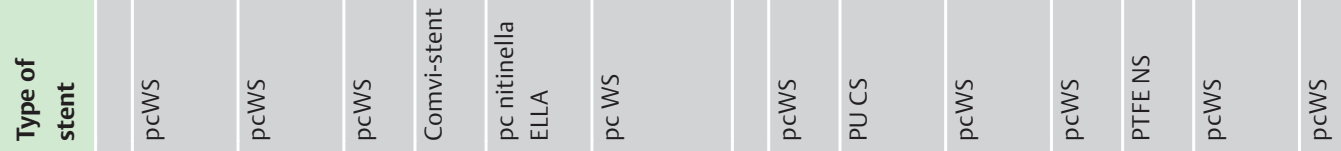

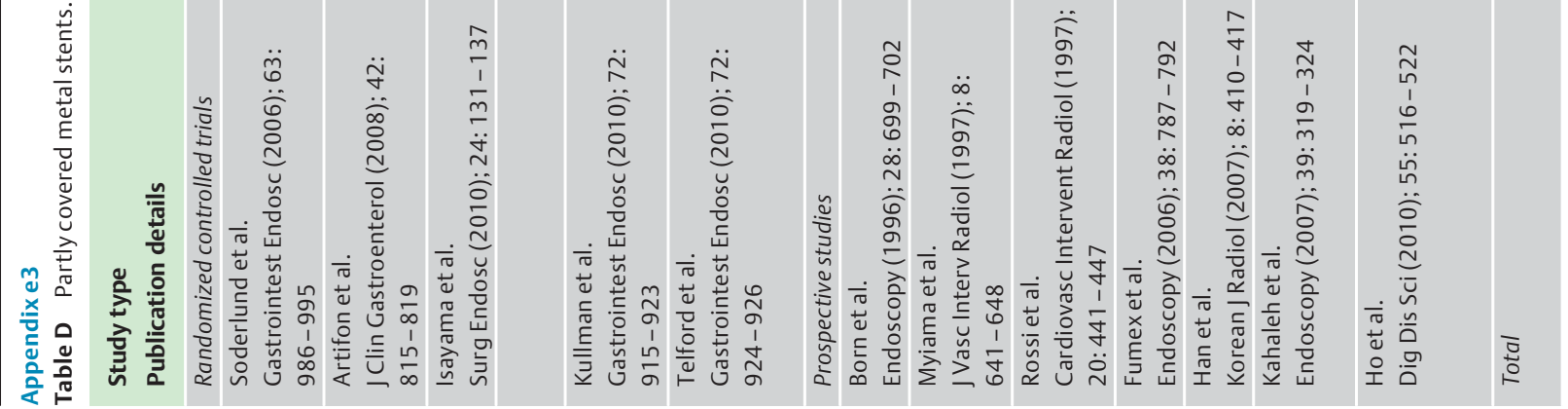



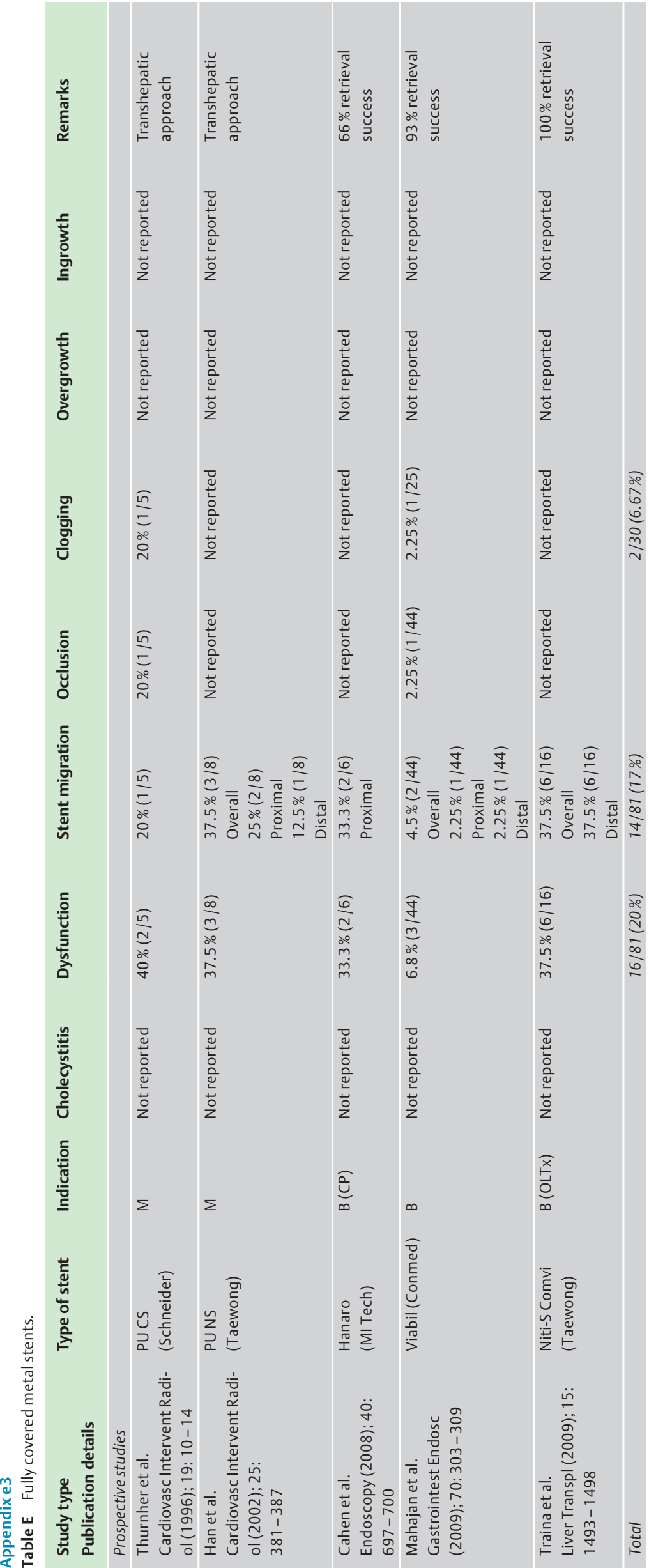